\title{
Probability Distribution and Determination of Blast Loading during Structural Blast Resistant Study
}

\author{
Taochun Yang $\mathbb{D},{ }^{1,2}$ Yaozhi Luo $\mathbb{D D}^{1}$ Guangqing $\mathrm{Hu}\left(\mathbb{D}{ }^{2}\right.$ and Yi Jiang $\mathbb{D}^{3}$ \\ ${ }^{1}$ College of Civil Engineering and Architecture, Zhejiang University, Hangzhou 310027, Zhejiang, China \\ ${ }^{2}$ School of Civil Engineering and Architecture, University of Jinan, Jinan 250022, Shandong, China \\ ${ }^{3}$ Ningbo Jiangong Engineering Group Co., Ltd, Ningbo 315040, Zhejiang, China
}

Correspondence should be addressed to Taochun Yang; yangtaochun@126.com

Received 11 November 2021; Accepted 10 January 2022; Published 11 February 2022

Academic Editor: Shan Gao

Copyright ( 12022 Taochun Yang et al. This is an open access article distributed under the Creative Commons Attribution License, which permits unrestricted use, distribution, and reproduction in any medium, provided the original work is properly cited.

Explosion overpressure and its duration are important parameters describing blast loading. However, their values obtained using the currently available methods differ significantly. To address this problem, we simulated the overpressure reflection coefficient (i.e., the ratio of reflection overpressure to incident overpressure) and fitted the analytical expressions to the test data. We then collected a large amount of theoretical and experimental blast loading data from literature and studied the probability distribution of blast loading for different scaled distances. The results show that the probability density function of explosion overpressure obeys an exponential distribution when the scaled distance is between $0.1 \mathrm{~m} / \mathrm{kg}^{1 / 3}$ and $0.5 \mathrm{~m} / \mathrm{kg}^{1 / 3}$. On the other hand, it obeys a normal distribution when the scaled distance is greater than $0.5 \mathrm{~m} / \mathrm{kg}^{1 / 3}$. The coefficient of variation reaches the maximum value of 1 when the scaled distance is between $0.1 \mathrm{~m} / \mathrm{kg}^{1 / 3}$ and $0.5 \mathrm{~m} / \mathrm{kg}^{1 / 3}$, while it is between 0.13 and 0.2 when the scaled distance is from $1.5 \mathrm{~m} / \mathrm{kg}^{1 / 3}$ to $6 \mathrm{~m} / \mathrm{kg}^{1 / 3}$. The coefficient of variation of reflected overpressure is slightly bigger than that of incident overpressure. Nevertheless, the coefficient of variation of proportional duration (i.e., the ratio of actual duration to cubic root of charge mass) is generally smaller, between 0.408 and 1.017. It was also found that there is no clear probability distribution for the blast loading duration. Finally, formulas for the explosion overpressure and proportional duration were determined together with their 95\% confidence level bounds.

\section{Introduction}

With the continuous occurrence of terrorist attacks and accidental explosions, the research on blast resistance of building structures has become an important topic in civil engineering. Especially since the 9/11 incident, a significant amount of research has been carried out worldwide on blast resistance of building structures, including blast loading, structural dynamic response, failure modes, simplified calculation methods, blast resistance analysis methods, and blast resistance reinforcement measures. This led to formulating important guidelines for the blast resistance of engineering structures.
The accuracy of blast loading estimation directly affects the results of blast resistant design and is, therefore, the core consideration. A significant amount of research on the blast loading itself has been conducted, and relevant specifications have been formulated to provide efficient guidance for blast resistant design of structures. These guidelines include Fundamentals of Protective Design for Conventional Weapons TM5-855-1 [1], Structures to Resist the Effects of Accidental Explosion TM5-1300 [2], Design of Buildings to Resist Progressive Collapse UFC3-340-02 [3], Design and Assessment of Buildings Subjected to Blast Loads CSA/S85012 [4], China National Standards Blasting Safety Regulations GB6722-2014 [5], and Code for Design of Civil Air Defense 
Basement (GB50038-2005) [6]. These standards and specifications summarize theoretical research results and experimental data of blast loading in the form of formulas and graphs, which are widely used in blast resistant design and analysis.

Although calculation methods for blast loading are given in these specifications, the load values vary considerably, even by an order of magnitude, which makes selecting a design load calculation method challenging. Thus, probabilistic models of blast loading calibrated using experimental data were proposed to account for the uncertainty. Low et al. [7] performed a statistical analysis of eight commonly used blast loading determination methods (including theoretical formulas, empirical methods, and experimental data) and found that when the scaled distance was in the range of $0.24-40 \mathrm{~m} / \mathrm{kg}^{1 / 3}$, the average coefficients of variation of overpressure and its duration were 0.3227 and 0.130 , respectively. Bogosian et al. [8] found that the coefficient of variation of overpressure was 0.24 when the scaled distance was in the range of $1.2-23.8 \mathrm{~m} / \mathrm{kg}^{1 / 3}$. Li et al. [9-11] established a relationship between the average value, standard value, and coefficient of variation of the reflected overpressure and the scaled distance from a statistical analysis of 77 samples of blast loading data and applied them to the reliability analysis of steel beams. The obtained formulas for the reflection overpressure and its duration used a $90 \%$ confidence level and can be used for the calculation of blast loading values in building structural design. Thus, these results provided a good reference for the determination of loads in blast resistant design of building structures.

In the previous studies, the mean or variance of blast loading was calculated directly from discrete random data, or the blast loading parameter variables were assumed to obey a normal distribution. The experimental values corresponding to different scaled distances were interpolated from small experimental samples. The reflection overpressure was also directly obtained from the incident overpressure using a theoretical formula without considering the actual changes in the reflection coefficient (the ratio of reflection overpressure to incident overpressure) [12]. Because of these shortcomings, in this paper, the relevant blast resistance specifications, theoretical formulas, and experimental datasets on the explosion overpressure and its duration are reviewed. The reflection overpressure is determined using the reflection coefficient obtained experimentally. The measured blast impulse is converted into an equivalent triangle impulse. From the overpressure and proportional duration (i.e., the ratio of actual duration to cubic root of charge mass) data and histograms for different scaled distances, probability distribution for the explosion overpressure and proportional duration for different scaled distances are determined and validated. The maximum likelihood estimators of the overpressure parameters are obtained and their variations are analyzed. Finally, formulas and confidence intervals for the incident overpressure, reflected overpressure, and proportional duration are given.

\section{Blast Loading Characteristics}

Explosions produce extremely high-pressure and hightemperature gases. As their volume expands rapidly, air shock waves are formed in front of the compressed gas. The overpressure is a part of the shock wave pressure exceeding the ambient air pressure. The overpressure value decays rapidly with time. When the pressure drops below the ambient air pressure, a negative pressure zone is formed. The overpressure attenuation curve of a typical shock wave is shown in Figure 1. In structural blast resistant design, this negative pressure is often ignored; thus, the main relevant physical parameters are the positive overpressure, its duration, and impulse of blast loading. The common exponential attenuation function is as follows:

$$
P(t)=P_{s}^{+}\left(1-\frac{t}{T^{+}}\right) e^{-\zeta t / T^{+}} .
$$

In the formula, $P_{s}^{+}$is the peak value of positive overpressure, $T^{+}$is the duration of positive overpressure, and $\zeta$ is the attenuation coefficient.

In engineering applications, to simplify the calculations, the overpressure attenuation curve is often simplified as an equivalent descending triangular model $[1,2,13,14]$, as shown in Figure 2. The equivalent triangular loads have the same overpressure peak value, but different simplifications of their duration are adopted according to the expected time of the maximum response of the structure considered as follows: when the maximum response of the structure or component occurs at an early stage of the overpressure application, it is assumed that the slope of the triangular loads is tangent to the actual overpressure curve, and the equivalent action duration is denoted as $T_{a 1}$. This method is often used for long explosion relative to the time of the maximum structural response. When the maximum response of the structure or component occurs after the overpressure drops to zero, it is necessary to ensure that the triangular impulse is consistent with the actual overpressure impulse. The equivalent action time is denoted as $T_{a 2}$, and this method is often used for short explosion relative to the time of the maximum structural response. For the intermediate cases, it is assumed that the triangular impulse passes through $P_{s}^{+} / 2$ of the actual overpressure time history plot to calculate the duration $T_{a 3}$. For the commonly used advanced explosives, the second simplified method for obtaining the equivalent impulse is often used because the overpressure action time is often very short compared to the relative time of structural response.

\section{Explosion Overpressure Study}

3.1. Theoretical Overpressure Data. A large number of researchers, including Brode [15-17], Henrych [18, 19], Mills [12], Kinney [20], and Newmark [21], studied the shock wave overpressure and derived formulas by introducing empirical coefficients under ideal air explosion conditions. However, there are still significant differences among the different formulas, especially close to the explosion center, as 


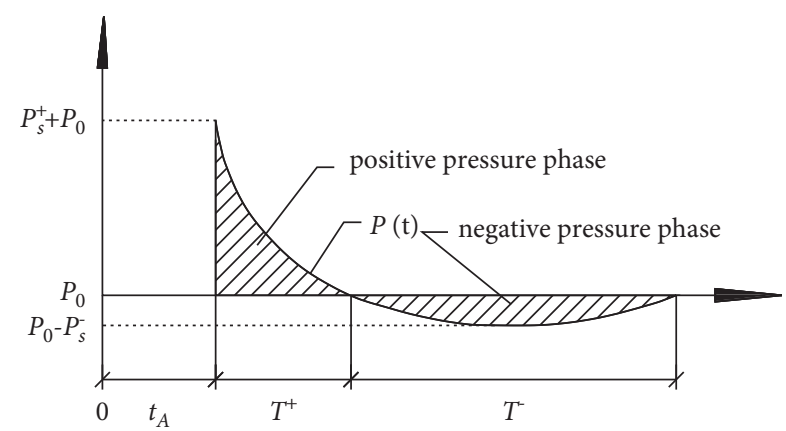

Figure 1: Exponential overpressure attenuation diagram.

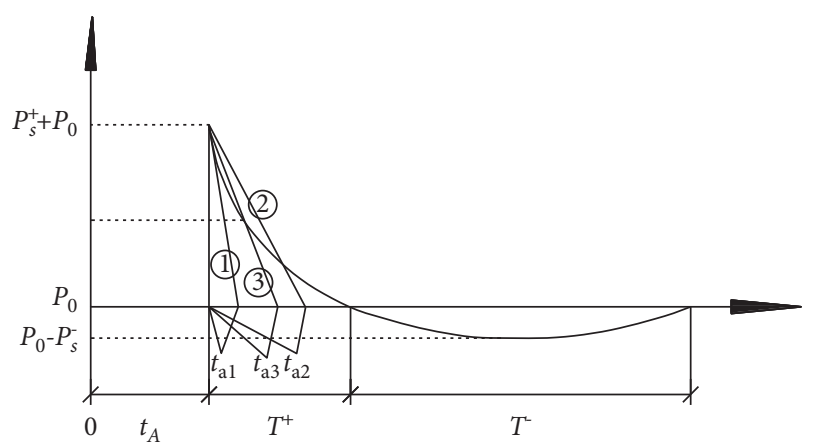

Figure 2: Triangle explosion overpressure equivalent diagram.

shown in Figure 3. Therefore, this study examined as many as 17 commonly used explosion overpressure formulas, as shown in (2)-(18). Of them, (2)-(17) can be used to directly calculate the incident overpressure, and (18) can be used to directly calculate the reflected overpressure.

Kinney et al. [20] gave the formula for calculating peak incident overpressure (Mpa) under free air explosion as follows:

$\frac{P_{0}}{P_{\text {air }}}=\frac{808\left[1+(Z / 4.5)^{2}\right]}{\left[1+(Z / 0.048)^{2}\right]\left[1+(Z / 0.32)^{2}\right]\left[1+(Z / 1.35)^{2}\right]}$.

Henrych et al. [18, 19] gave the expression of incident overpressure peak (bar) for ideal air explosion based on the experimental method as follows:

$$
P_{0}= \begin{cases}\frac{14.0717}{Z}+\frac{5.5397}{Z^{2}}-\frac{0.3572}{Z^{3}}+\frac{0.00625}{Z^{4}}, & 0.05 \leq Z \leq 0.3, \\ \frac{6.1938}{Z}-\frac{0.3262}{Z^{2}}+\frac{2.1324}{Z^{3}}, & 0.3 \leq Z \leq 1, \\ \frac{0.662}{Z}+\frac{4.05}{Z^{2}}+\frac{3.288}{Z^{3}}, & 1 \leq Z \leq 10 .\end{cases}
$$

Baker et al. [22] gave the expression of incident overpressure peak (MPa) for ideal air explosion as follows:

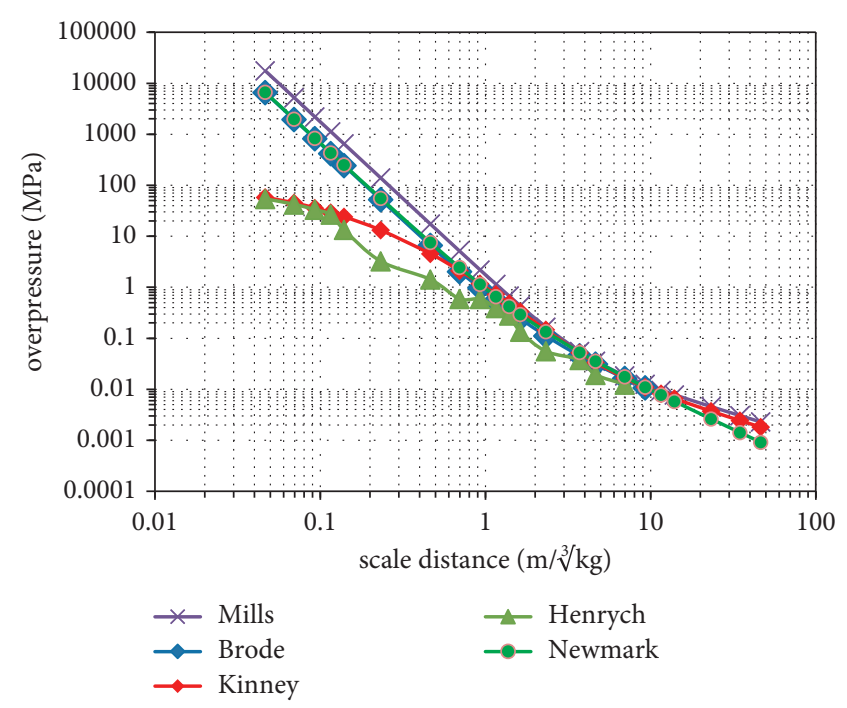

Figure 3: Comparison results of different overpressure formulas.

$$
P_{0}= \begin{cases}\frac{2.006}{Z}+\frac{0.194}{Z^{2}}-\frac{0.004}{Z^{3}}, & 0.05 \leq Z \leq 0.5, \\ \frac{0.067}{Z}+\frac{0.301}{Z^{2}}+\frac{0.431}{Z^{3}}, & 1 \leq Z \leq 10 .\end{cases}
$$

$\mathrm{Wu}$ and How [23] gave the expression of incident overpressure peak $(\mathrm{MPa})$ during the ground explosion as follows:

$$
P_{0}= \begin{cases}\frac{1.059}{Z^{2.56}}-0.051, & 0.1 \leq Z \leq 1, \\ \frac{1.008}{Z^{2.01}}, & 1 \leq Z \leq 10 .\end{cases}
$$

Naumyenko et al. [19, 24, 25] gave the expression of incident overpressure peak (bar) under ideal air explosion according to the model similarity theory and determined the coefficients by experimental method. Among them, the first equation is obtained by Naumyenko and Petrovsky, and the second equation is derived by Sadovskii. The specific calculation expression is as follows:

$$
P_{0}= \begin{cases}\frac{10.7}{Z^{3}}-1, & Z \leq 1, \\ \frac{0.76}{Z}+\frac{2.55}{Z^{2}}+\frac{6.5}{Z^{3}}, & 1 \leq Z \leq 15 .\end{cases}
$$

Brode [15-17] gave the expression of incident overpressure peak (bar) for ideal air explosion by using similar model theory as follows:

$$
P_{0}= \begin{cases}\frac{6.7}{Z^{3}}+1, & P_{0}>10 \mathrm{bar}, \\ \frac{0.975}{Z}+\frac{1.455}{Z^{2}}+\frac{5.85}{Z^{3}}-0.019, & 0.1 \mathrm{bar}<P_{0}<10 \mathrm{bar} .\end{cases}
$$


Mills [12] combined the similarity theory and numerical simulation and gave the expression of incident overpressure peak $(\mathrm{MPa})$ for ideal air explosion as follows:

$$
P_{0}=\frac{0.108}{Z}-\frac{0.114}{Z^{2}}+\frac{1.772}{Z^{3}} \text {. }
$$

Ye [26] gave the expression of incident overpressure peak $(\mathrm{MPa})$ for ideal air explosion as follows:

$$
P_{0}=\frac{0.084}{Z}+\frac{0.27}{Z^{2}}+\frac{0.7}{Z^{3}} \text {. }
$$

The expression of incident overpressure peak (bar) for explosive ground explosion provided in Chinese National Standard Blasting Safety Regulations [5] is as follows:

$P_{0}=\frac{1.06}{Z}+\frac{4.3}{Z^{2}}+\frac{14}{Z^{3}}, \quad \frac{H}{\sqrt[3]{W}} \leq 0.35,1 \leq Z \leq 10 \sim 15$.

The expression of incident overpressure peak ( $\mathrm{MPa})$ for explosive ground explosion provided in the National Standard Code for Design of Civil Air Defense Basement [6] is as follows:

$$
P_{0}=\frac{0.369}{Z^{3 / 2}}+\frac{1.316}{Z^{3}}
$$

The expression of incident overpressure peak $(\mathrm{MPa})$ for ground explosion proposed by Newmark and Hansen [21] is as follows:

$$
P_{0}=\frac{0.294}{Z^{1.5}}+\frac{0.6784}{Z^{3}} \text {. }
$$

Siddiqui [27] Ahmad [28], and Iqbal [29] gave the expressions of incident overpressure peak ( $\mathrm{MPa})$ for ground explosion based on experimental data as follows:

$$
\begin{gathered}
P_{0}=1.017 \cdot Z^{-1.91}, \quad 1 \leq Z \leq 12, \\
P_{0}=2.46 \cdot Z^{-2.67}, \\
P_{0}=1.026 \cdot Z^{-1.96}, \quad 1 \leq Z \leq 12 .
\end{gathered}
$$

The expression of incident overpressure peak $(\mathrm{KPa})$ of air explosion given in the US military protection technology manual TM5-855-1 [1] is as follows:

$$
P_{0}=\frac{39.5}{Z}-\frac{105}{Z^{2}}+\frac{4120}{Z^{3}}, \quad 2<P_{0}<160,3 \leq Z \leq 20 .
$$

Held et al. [30] gave the expression of incident overpressure peak $(\mathrm{MPa})$ in air explosion based on theoretical analysis as follows:

$$
\begin{aligned}
P_{0} & =\mathrm{A} \cdot Z^{-2}, \quad 0.6 \leq \mathrm{A} \leq 6, \bar{A} \\
& =2 .
\end{aligned}
$$

The expression of reflection overpressure peak $(\mathrm{KPa})$ for ground explosions given in the Canadian specification CSA/S 850-12 [4] is as follows:

$$
\ln P_{r}= \begin{cases}8.9973-2.6077 \ln Z-0.5045 \ln ^{2} Z-0.0588 \ln ^{3} Z, & 0.06<Z \leq 1.95 \\ 9.7457-4.7276 \ln Z+1.1734 \ln ^{2} Z-0.1337 \ln ^{3} Z, & 1.95<Z<39.67\end{cases}
$$

It can be seen that there is a very limited number of theoretical or empirical formulas for the reflection overpressure; thus, more reflection overpressure data need to be obtained using the reflection coefficient and the incident overpressure. Mills proposed a theoretical expression for the reflection coefficient, as shown in (19). In the US Military Protection Technology Manual TM5-855-1 [1], the variation of reflection coefficient with the incident angle is considered (Figure 4). A comparison of the reflection coefficients obtained by (19) and Figure 4 is shown in Figure 5 for the vertical incident angle $\left(0^{\circ}\right)$. Figure 5 shows that when the incident overpressure is small, the theoretical and experimental reflection coefficients are equal. However, when the incident overpressure is large, the maximum experimental reflection coefficient is 13.2 , which is much larger than the theoretical value of 8 . Therefore, when the reflection overpressure is calculated using the incident overpressure and the reflection coefficient, the reflection coefficient should be determined according to the experimental value. To obtain the experimental reflection coefficient conveniently for the case of vertical incidence, a formula for the reflection coefficient, $\mu$, for different overpressures obtained by fitting experimental data is shown in (20), and the regression coefficient is 0.9871 , as shown in the imaginary line in Figure 5. Thus, the relationship formula equation (21) between the reflection overpressure and the incident overpressure is obtained.

$$
\begin{aligned}
P_{r} & =2 P_{0} \cdot \frac{7 P_{\mathrm{air}}+4 P_{0}}{7 P_{\mathrm{air}}+P_{0}}, \\
\mu & =5.3104 \cdot P_{0}^{0.2356}(\mathrm{MPa}), \\
P_{r} & =\mu P_{0} \\
& =5.3104 \cdot P_{0}^{1.2356}(\mathrm{MPa}) .
\end{aligned}
$$

3.2. Experimental Overpressure Data. Several researchers have carried out field blast resistant tests. The test data gathered will help to analyze the explosion overpressure more accurately. In this study, 125 reliable explosion overpressure experimental datasets were collected from literature. The data cover the charge mass from $30 \mathrm{~g}$ to $50 \mathrm{~kg}$, 


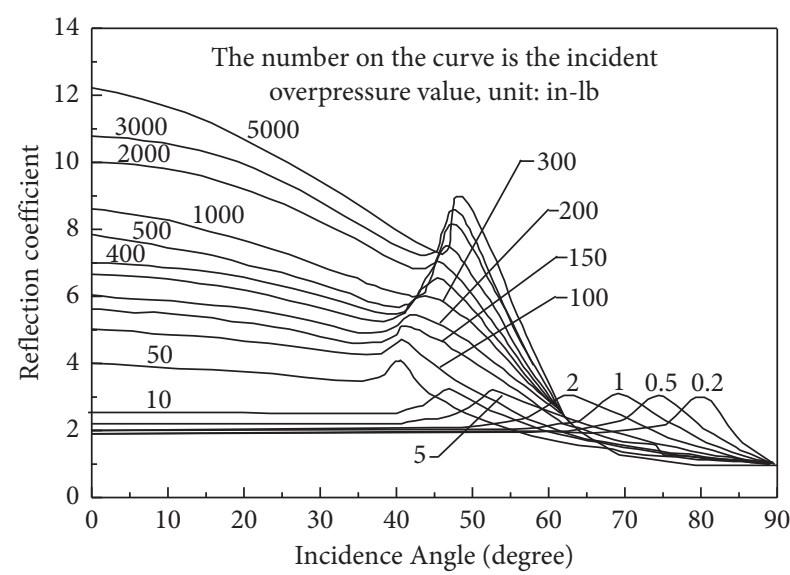

FIgURE 4: Relationship between reflection coefficient and incident angle [1].

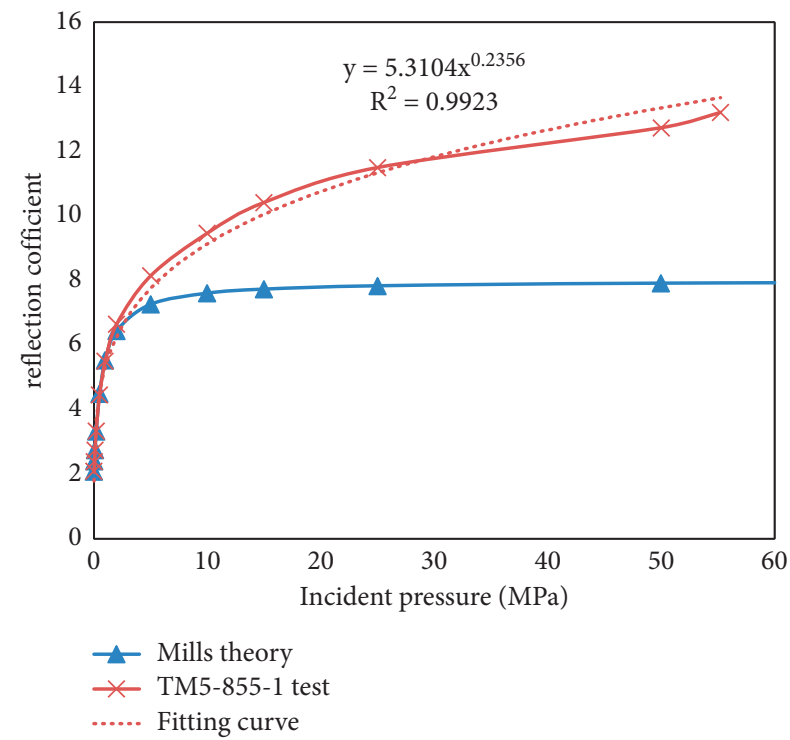

Figure 5: Comparison results between theory and experimental values of reflection coefficients.

and the scaled distance from 0.295 to $55 \mathrm{~m} / \mathrm{kg}^{1 / 3}$, as shown in Table 1. It can be seen from the table that the blast loading is sensitive to the environmental factors, and the overpressure values obtained by multiple tests under the same conditions are different. The explosion distances in the tests were relatively small, mostly within $5 \mathrm{~m}$, which was mainly because of the small equivalent explosive masses and desire to reduce the influence of environmental factors. At the same time, considering the stability and accessibility of explosives, some tests used ANFO explosives (equivalent coefficient of 0.82), emulsion explosives (0.71), Composite C-4 (1.37), and Gelamon VF80 (0.8), rather than TNT explosives, which also increased the variability of the test data. In some tests, the charge was placed at a certain height from the ground, and the reflection of the shock wave off the ground also affected the overpressure. In some tests, the charge shape was nonspherical or irregular, especially when the equivalent explosive mass was small, which had some influence on the overpressure. Therefore, for the experimental explosion data listed in Table 1, the above factors cannot be completely avoided, and these differences are also important factors leading to explosion overpressure uncertainty.

In the collected experimental datasets, there are both vertical and nonvertical incidence cases. However, for the sake of consistency, only the vertical incidence cases were retained for analysis. Furthermore, some datasets had only the incident overpressure samples, some had only the reflected overpressure samples, and only 11 datasets had both the incident and the reflected overpressure. For the same batch of tests, 22 datasets exhibited significant differences and were excluded from the subsequent analysis. Eventually, a total of 103 datasets were used.

The existing formulas for the incident explosion overpressure (2)-(18) have the general forms as shown in (22) and (23). In each formula, there are three undetermined coefficients. Equation (22) is obtained from the mechanical explosion theory and its correlation coefficient is determined by experiments. This method has been more widely applied in the existing formula for the incident overpressure. Equation (23) is obtained by fitting the experimental data, and it also has certain applications. Therefore, the reflection coefficient formula (20) and the incident overpressure formula (22) can be used together to gain the overpressure data under certain scaled distance, which provides statistical samples for analyzing the probability distribution of the explosion overpressure.

$$
\begin{aligned}
& P_{0}=\frac{a}{Z}+\frac{\mathrm{b}}{Z^{2}}+\frac{c}{Z^{3}}, \\
& P_{0}=\mathrm{d} \cdot Z^{\mathrm{e}}+f .
\end{aligned}
$$

3.3. Overpressure Probability Distribution. Using the explosion overpressure data, histograms corresponding to different blast scaled distances were drawn. In addition to the distribution characteristics observed in the histograms, the K-S and Lilliefors goodness-of-fit tests of overpressure probability distribution for different scaled distances were carried out. The results showed that when the scaled distance was less than $0.5 \mathrm{~m} / \mathrm{kg}^{1 / 3}$, the incident and reflected overpressure both followed exponential distributions. However, when the scaled distance was greater than $0.5 \mathrm{~m} / \mathrm{kg}^{1 / 3}$, the overpressure distributions were normal. Using these probability distributions, the maximum likelihood estimates of the expectation and standard deviation of the overpressure for different scaled distances were calculated. Furthermore, the $95 \%$ confidence interval of the overpressure was obtained, as shown in Tables 2 and 3. Then, the probability density functions (exponential and normal) of overpressure for different scaled distances were drawn as shown in Figures 6 and 7. It can be seen from Tables 2 and 3 that when the scaled distance is small, the standard deviation is the largest, and thus the overpressure distribution is wider.

To compare the dispersion degree of the incident and reflected overpressure for different scaled distances, the 


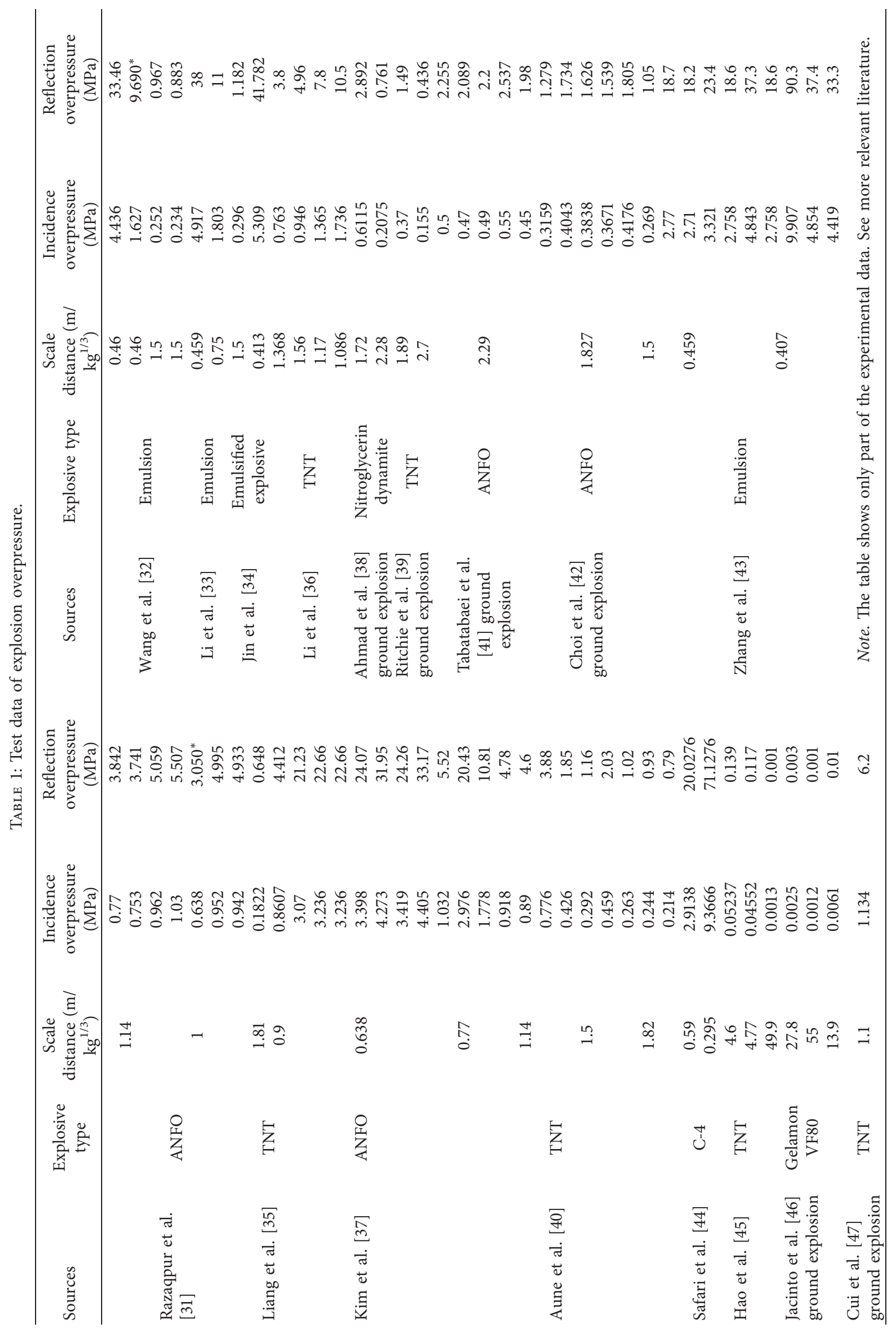


TABLE 2: Maximum likelihood estimate of expectation and standard deviation for incident overpressure.

\begin{tabular}{|c|c|c|c|c|c|c|c|}
\hline Scaled distance $\left(\mathrm{m} / \mathrm{kg}^{1 / 3}\right)$ & 0.100 & 0.300 & 0.407 & 0.459 & 0.638 & 0.770 & 1.000 \\
\hline Expectation $(\mathrm{MPa})$ & 440.4414 & 20.3322 & 7.702 & 6.0207 & 3.1478 & 1.7251 & 0.9203 \\
\hline \multirow{2}{*}{ Expected confidence interval (MPa) } & 273.1539 & 12.8046 & 5.1916 & 3.9815 & 2.6001 & 1.4177 & 0.8079 \\
\hline & 827.1854 & 37.1902 & 12.6091 & 10.1586 & 3.6955 & 2.0325 & 1.0327 \\
\hline Standard deviation (MPa) & 440.4414 & 20.3322 & 7.702 & 6.0207 & 1.2032 & 0.5769 & 0.2661 \\
\hline Scaled distance $\left(\mathrm{m} / \mathrm{kg}^{1 / 3}\right)$ & 1.140 & 1.500 & 1.540 & 1.600 & 1.820 & 1.930 & 2.280 \\
\hline Expectation $(\mathrm{MPa})$ & 0.7078 & 0.354 & 0.3541 & 0.3144 & 0.2306 & 0.2012 & 0.1403 \\
\hline \multirow{2}{*}{ Expected confidence interval (MPa) } & 0.6328 & 0.3196 & 0.3299 & 0.2855 & 0.2142 & 0.1853 & 0.1312 \\
\hline & 0.7828 & 0.3884 & 0.3783 & 0.3433 & 0.247 & 0.2171 & 0.1494 \\
\hline Standard deviation $(\mathrm{MPa})$ & 0.1776 & 0.0833 & 0.0636 & 0.0617 & 0.037 & 0.0319 & 0.0183 \\
\hline Scaled distance $\left(\mathrm{m} / \mathrm{kg}^{1 / 3}\right)$ & 3.880 & 4.030 & 5.000 & 8.000 & 10.000 & 11.700 & 15.000 \\
\hline Expectation $(\mathrm{MPa})$ & 0.0487 & 0.045 & 0.0299 & 0.0134 & 0.0096 & 0.0074 & 0.0056 \\
\hline \multirow{2}{*}{ Expected confidence interval (MPa) } & 0.0447 & 0.0415 & 0.0277 & 0.0119 & 0.0081 & 0.006 & 0.004 \\
\hline & 0.0527 & 0.0485 & 0.032 & 0.0148 & 0.0111 & 0.0088 & 0.0072 \\
\hline Standard deviation (MPa) & 0.008 & 0.007 & 0.0042 & 0.0028 & 0.0027 & 0.0024 & 0.0022 \\
\hline
\end{tabular}

TABLE 3: Maximum likelihood estimate of expectation and standard deviation for reflection overpressure.

\begin{tabular}{|c|c|c|c|c|c|c|c|}
\hline Scaled distance $\left(\mathrm{m} / \mathrm{kg}^{1 / 3}\right)$ & 0.100 & 0.300 & 0.407 & 0.459 & 0.638 & 0.770 & 1.000 \\
\hline Expectation $(\mathrm{MPa})$ & 11577.00 & 236.9497 & 70.2371 & 51.2193 & 22.3138 & 10.5674 & 4.8446 \\
\hline \multirow{2}{*}{ Expected confidence interval (MPa) } & 7180 & 149.2234 & 47.3442 & 33.8719 & 17.4063 & 8.2035 & 4.093 \\
\hline & 21742 & 433.4107 & 114.9871 & 86.4223 & 27.2214 & 12.9312 & 5.5962 \\
\hline Standard deviation (MPa) & 11577.00 & 236.9497 & 70.2371 & 51.2193 & 10.7812 & 4.4361 & 1.7799 \\
\hline Scaled distance $\left(\mathrm{m} / \mathrm{kg}^{1 / 3}\right)$ & 1.140 & 1.500 & 1.540 & 1.600 & 1.820 & 1.930 & 2.280 \\
\hline Expectation $(\mathrm{MPa})$ & 3.494 & 1.483 & 1.4789 & 1.2777 & 0.8698 & 0.7349 & 0.4701 \\
\hline \multirow{2}{*}{ Expected confidence interval (MPa) } & 3.0308 & 1.3041 & 1.3542 & 1.132 & 0.7934 & 0.6634 & 0.4328 \\
\hline & 3.9571 & 1.6618 & 1.6036 & 1.4233 & 0.9463 & 0.8064 & 0.5074 \\
\hline Standard deviation $(\mathrm{MPa})$ & 1.0968 & 0.4333 & 0.3279 & 0.3112 & 0.1724 & 0.1438 & 0.0751 \\
\hline Scaled distance $\left(\mathrm{m} / \mathrm{kg}^{1 / 3}\right)$ & 3.880 & 4.030 & 5.000 & 8.000 & 10.000 & 11.700 & 15.000 \\
\hline Expectation $(\mathrm{MPa})$ & 0.1274 & 0.1155 & 0.0695 & 0.0258 & 0.0172 & 0.0126 & 0.0089 \\
\hline \multirow{2}{*}{ Expected confidence interval (MPa) } & 0.1142 & 0.1043 & 0.0634 & 0.0225 & 0.014 & 0.0098 & 0.006 \\
\hline & 0.1405 & 0.1268 & 0.0756 & 0.0292 & 0.0205 & 0.0154 & 0.0118 \\
\hline Standard deviation $(\mathrm{MPa})$ & 0.0264 & 0.0227 & 0.0118 & 0.0065 & 0.0056 & 0.0048 & 0.0041 \\
\hline
\end{tabular}

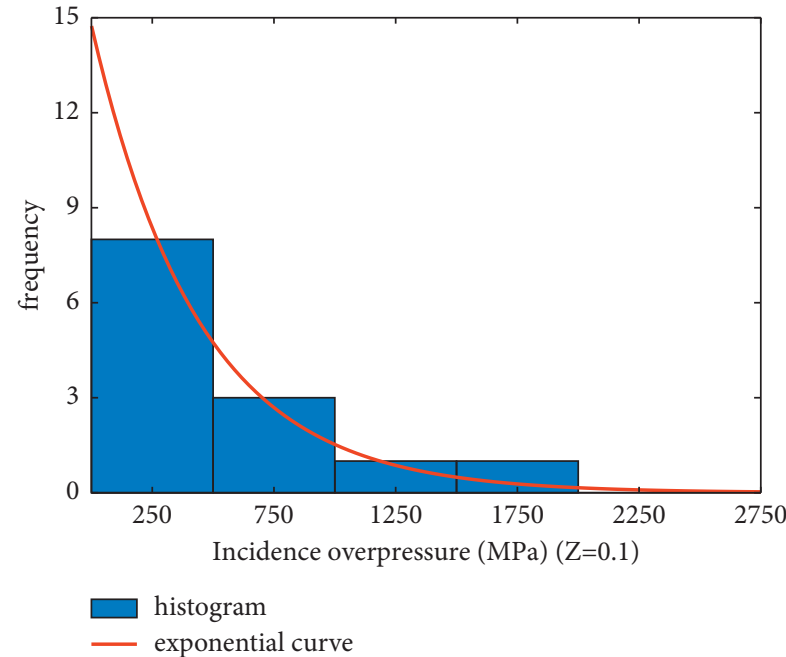

(a)

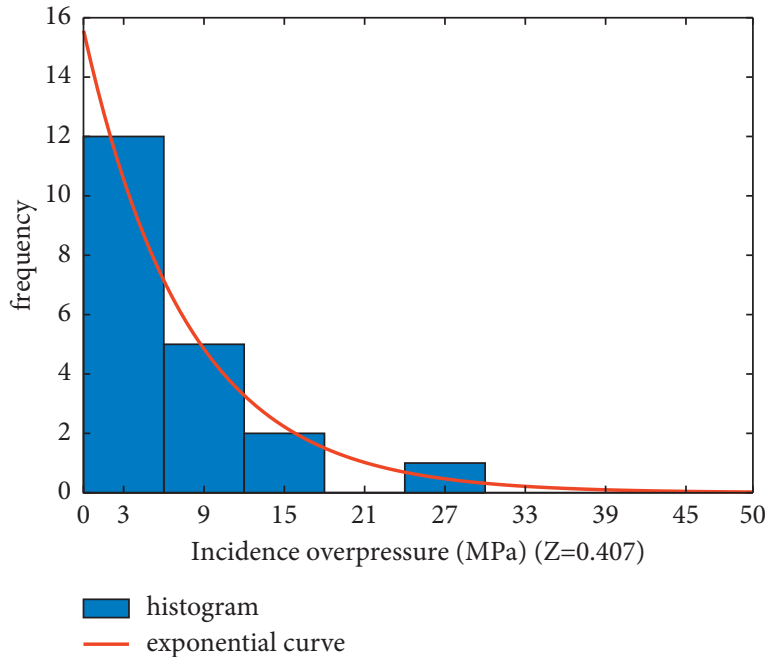

(b)

Figure 6: Continued. 


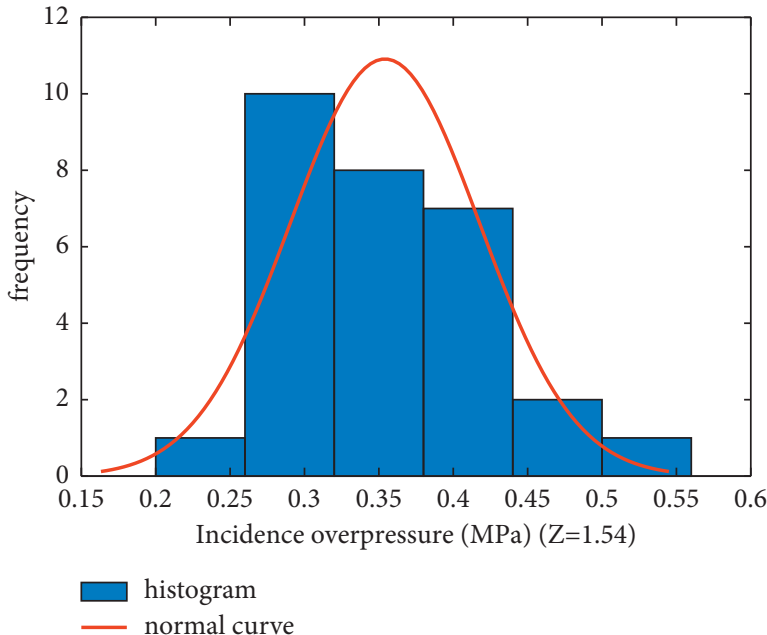

(c)

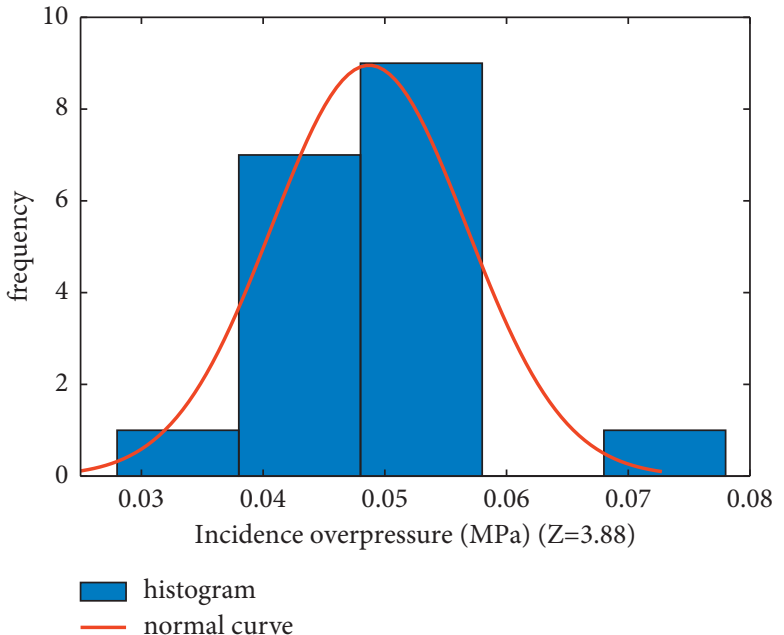

(d)

Figure 6: Histogram and probability density curve of incident overpressure under different scaled distance. (a) $Z=0.1$. (b) $Z=0.407$. (c) $Z=1.54$. (d) $Z=3.88$.

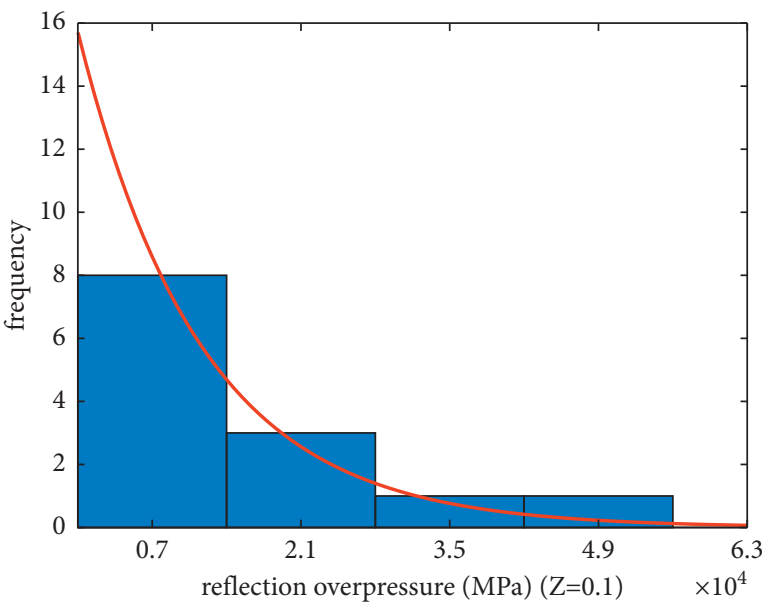

histogram

exponential curve

(a)

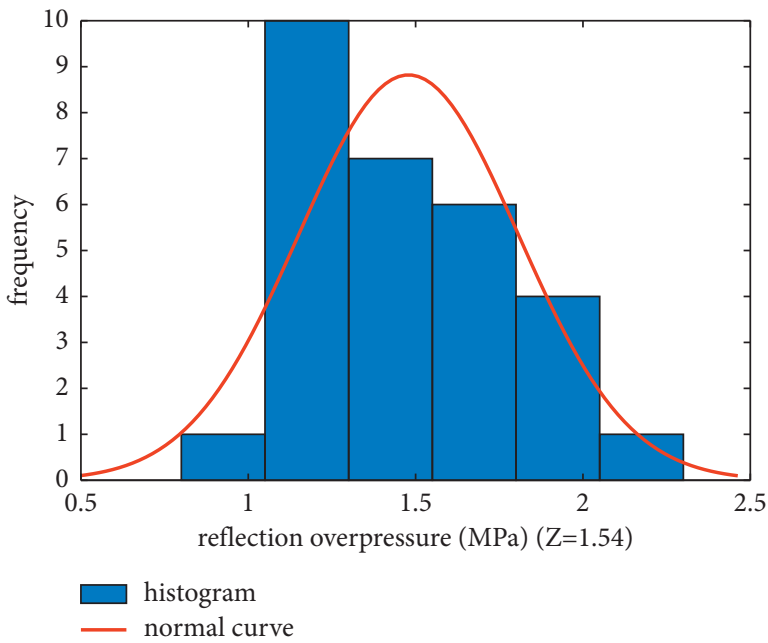

(c)

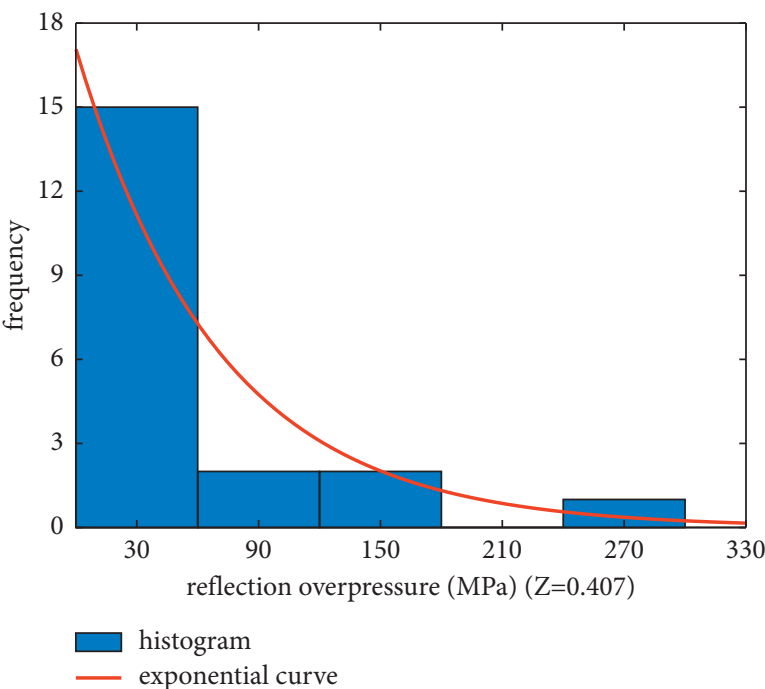

(b)

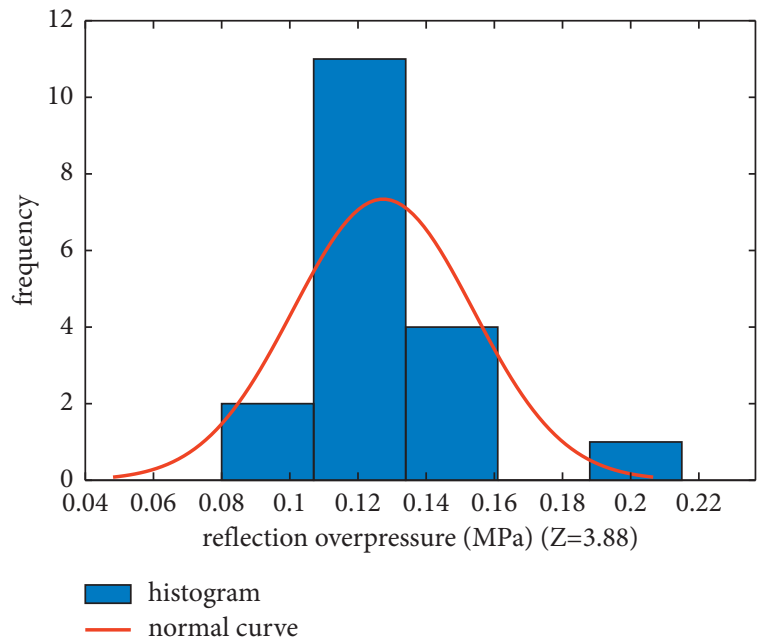

(d)

FIgURE 7: Histogram and probability density curve of reflection overpressure under different scaled distance. (a) $Z=0.1$. (b) $Z=0.407$. (c) $Z=1.54$. (d) $Z=3.88$. 
coefficients of variation of overpressure distribution were obtained from the expectations and standard deviations in Tables 2 and 3, as shown in Figure 8. It can be seen from Figure 8 that when the scaled distance was less than $0.5 \mathrm{~m} / \mathrm{kg}^{1 / 3}$, the coefficient of variation of overpressure reached the maximum value of 1 , which is constant of the exponential distribution. When the scaled distance was about $1.5-6 \mathrm{~m} / \mathrm{kg}^{1 / 3}$, the coefficient of variation was small due to more experimental data. In the range $0.13-0.2 \mathrm{~m} / \mathrm{kg}^{1 / 3}$, the coefficient of variation of the reflection overpressure was slightly larger than that of the incident overpressure.

3.4. Determination of Overpressure Formula. Using the maximum likelihood estimations of the overpressure expectations shown in Tables 2 and 3, the relationships between the upper and lower $95 \%$ confidence limits of the incident and reflected overpressure and the scaled distance can be obtained, as shown in Figures 9 and 10, respectively. Since the overpressure values for different scaled distances varied considerably, the scaled distances are plotted in three sections. It can be seen from the figure that the smaller the scaled distance, the more dispersed the overpressure distribution. A polynomial was fitted to the natural logarithm of the scaled distance and overpressure data using the least square method. As shown in Figures 11 and 12, the regression coefficients of the fitted curves of the incident and the reflected overpressure are greater than 0.99 .

Finally, the formula for calculating incidence overpressure is as follows:

$$
\ln P_{0}=0.1583 \ln ^{2} Z-2.342 \ln Z-0.0977 .
$$

The upper and lower limits of $95 \%$ confidence interval for incidence overpressure are calculated as follows:

$$
\ln P_{0}=0.2149 \ln ^{2} Z-2.4867 \ln Z+0.0711 \text { (upper.limit), }
$$

$\ln P_{0}=0.1111 \ln ^{2} Z-2.2428 \ln Z-0.2506$ (lower.limit).

Similarly, the formula for calculating reflection overpressure is as follows:

$$
\ln P_{r}=0.2087 \ln ^{2} Z-2.9263 \ln Z+1.5647 .
$$

The upper and lower limits of $95 \%$ confidence interval for reflection overpressure are calculated as follows:

$$
\begin{aligned}
& \ln P_{r}=0.2643 \ln ^{2} Z-3.0652 \ln Z+1.7512 \text { (upper.limit), } \\
& \ln P_{r}=0.162 \ln ^{2} Z-2.8339 \ln Z+1.3898 \text { (lower.limit). }
\end{aligned}
$$

In practical engineering applications, the recommended values of incident and reflected overpressure are calculated using (24) and (27), respectively. When there is sufficient experience supported by data, (25), (26), (28), and (29) can be used as the $95 \%$ confidence upper and lower limits of the overpressures under such conditions. It should be noted that when the scaled distance is very small $\left(<0.1 \mathrm{~m} / \mathrm{kg}^{1 / 3}\right)$, the explosion overpressures should be determined from special studies on the proximity or contact explosion.

\section{Explosion Duration Study}

4.1. Theoretical Duration Data. Duration is another important parameter of blast loading, and different formulas were proposed using theoretical derivations and experimental data, as shown in (30)-(39). The relationships between the blast loading and time use either the actual exponential form (Figure 1) or simplified triangular form (Figure 2). The Code for Design of Civil Air Defense Basement [6], Held [30], and Canadian specification CSA/ S850-12 [4] all use triangular form, while some other sources use the exponential form. In the statistics of theoretical data, the most used Conwep program calculation results are included. Then, taking $25 \mathrm{~kg}$ and $50 \mathrm{~kg}$ explosive equivalents as examples, the relationships between the duration and scaled distance for different explosive equivalents are shown in Figure 13. It can be seen that the overpressure durations for the different conditions are also quite different; thus, it is necessary to carry out statistical analysis on the duration of blast loading. It can be seen from the formulas that the duration, $t$, is mainly related to the explosive equivalent and scaled distance. Using the similarity rate, the functional relationship between parameter $t / \sqrt[3]{W}$ and the scaled distance can be obtained, and the statistical characteristics of the blast loading duration will be subsequently studied using this parameter.

For high-explosive TNT, Henrych $[18,19]$ obtained the calculation formula of overpressure duration for air explosion according to the experimental research work as follows:

$$
\begin{aligned}
\frac{t}{\sqrt[3]{W}}= & 0.107+0.444 Z+0.264 Z^{2}-0.129 Z^{3} \\
& +0.0334 Z^{4}, \quad 0.05 \leq Z \leq 3\left(\frac{\mathrm{ms}}{\mathrm{kg}^{1 / 3}}\right) .
\end{aligned}
$$

Sadovskii [25] gave the calculation formula of explosion overpressure duration under the condition of air explosion as follows:

$$
\frac{t}{\sqrt[3]{W}}=B \sqrt{R} \sqrt[6]{W}\left(\frac{\mathrm{ms}}{\mathrm{kg}^{1 / 3}}\right)
$$

For coefficient B, Naumyenko [24] recommended 1.0, Pokrovskii [48] considered 1.3, and Baum [49] gave 1.5.

According to Yang et al. [50], through the numerical simulation results of parameter analysis and fitting, the relationship of positive overpressure duration is as follows:

$$
\begin{aligned}
t= & 0.079946 Z^{0.85}(\text { ascent }) \\
& +0.71673 Z^{1.3425} W^{0.3136}(\text { downcomer })(\mathrm{ms})
\end{aligned}
$$




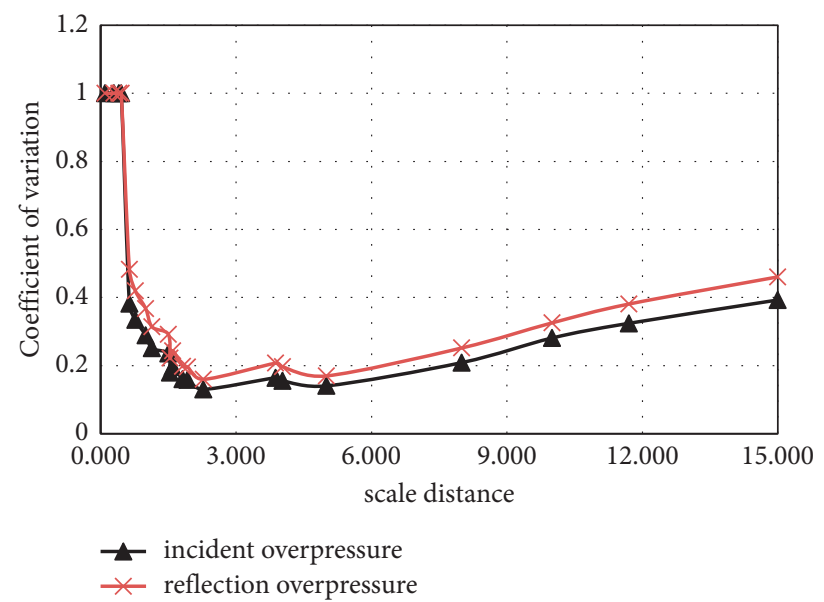

FIGURE 8: Variation coefficient of overpressure under different scaled distance.

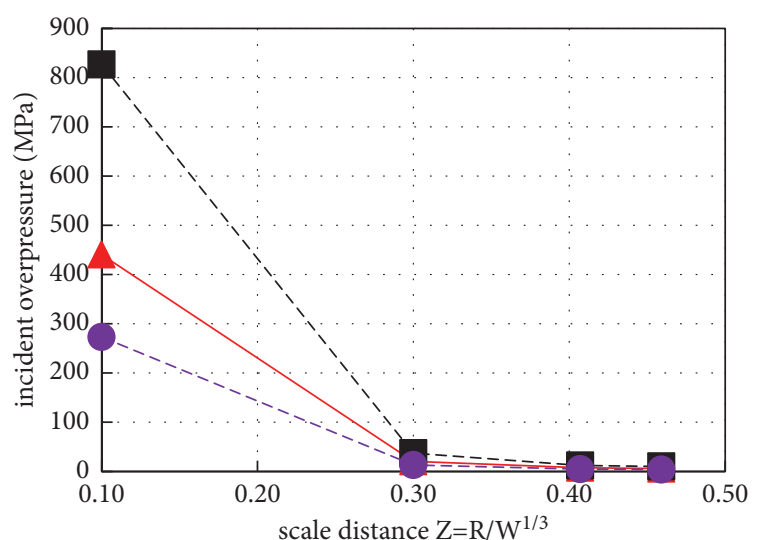

—- Incidence overpressure (expectation)

-ם- upper limit of $95 \%$ confidence interval

(a)

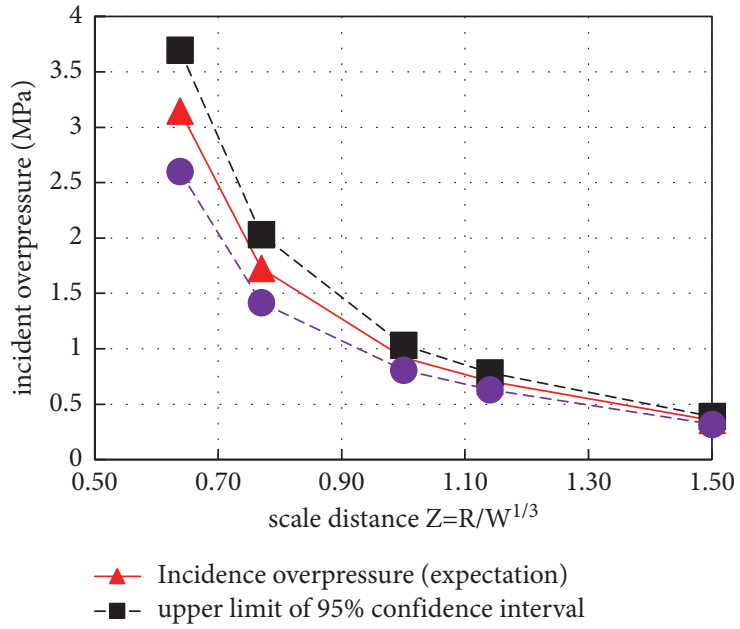

(b)

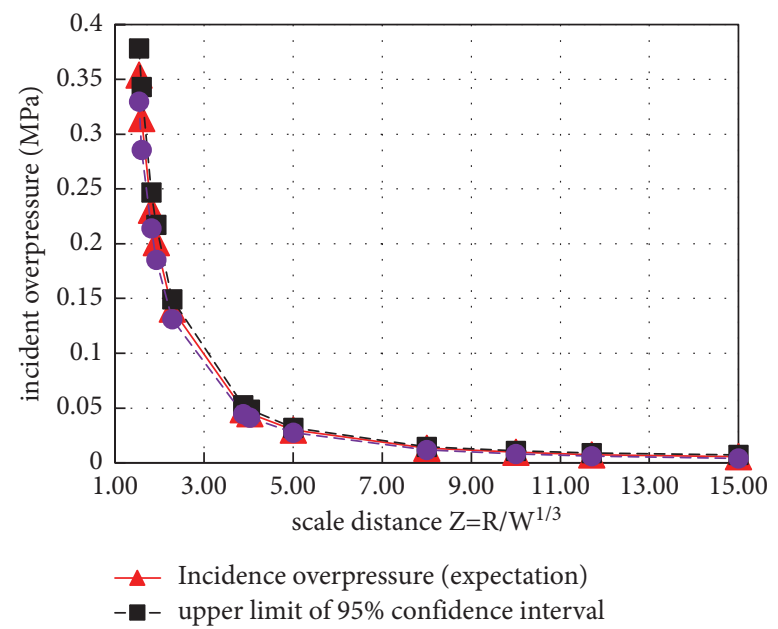

(c)

Figure 9: Change relation of incident overpressure, 95\% confidence interval with scaled distance. 


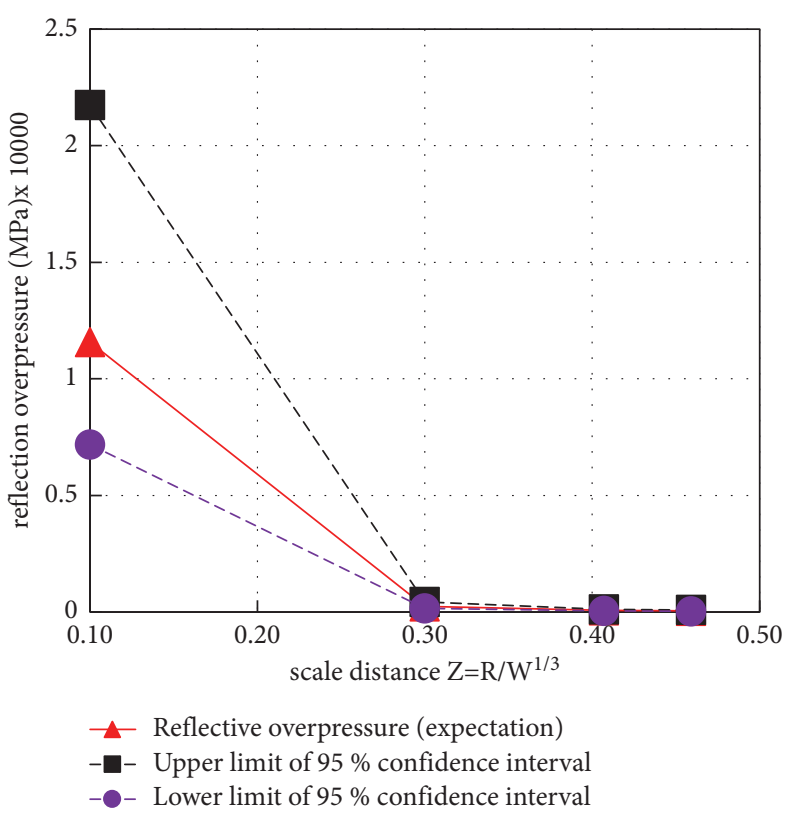

(a)

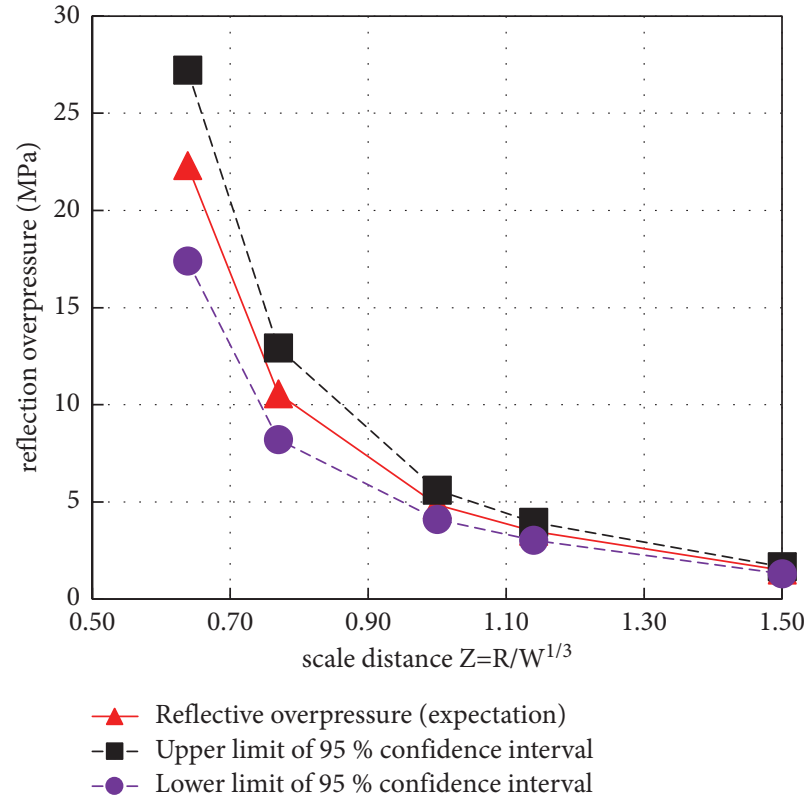

(b)

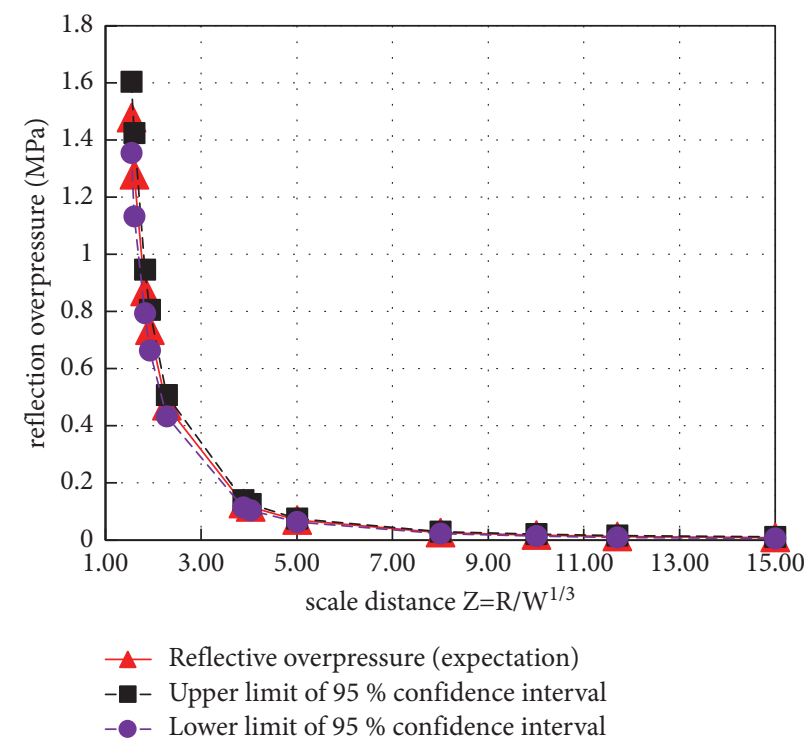

(c)

Figure 10: Change relation of reflection overpressure, $95 \%$ confidence interval with scaled distance. (a) $0.1 \leq \mathrm{Z} \leq 0.5$. (b) $0.5 \leq \mathrm{Z} \leq 1.5$. (c) $1.5 \leq \mathrm{Z} \leq 15$.

In the process of data calculation, the formula has serious deviation when the scaled distance is large, so only the scaled distance less than $3 \mathrm{~m} / \mathrm{kg}^{1 / 3}$ is considered.

In the China Code for the Design of Civil Air Defense Basement [6], the suggested overpressure duration formula for the ground explosion is as follows:

$$
\frac{t}{\sqrt[3]{W}}=\frac{0.4}{\sqrt{P_{r}}}
$$

where $P_{r}$ is reflected overpressure, the unit is $\mathrm{MPa}$, the unit of $t$ is $\mathrm{ms}$, and the unit of $w$ is $\mathrm{kg}$.
The calculation formula (triangular load) of incident overpressure and incident impulse of spherical explosive for air explosion given by Held [30] is as follows:

$$
\begin{gathered}
P_{s o}=\frac{2}{Z^{2}}, \\
\frac{i_{\text {so }}}{\sqrt[3]{W}}=\frac{300}{Z} .
\end{gathered}
$$

The duration after conversion is as follows:

$$
\frac{t}{\sqrt[3]{W}}=0.3 Z
$$




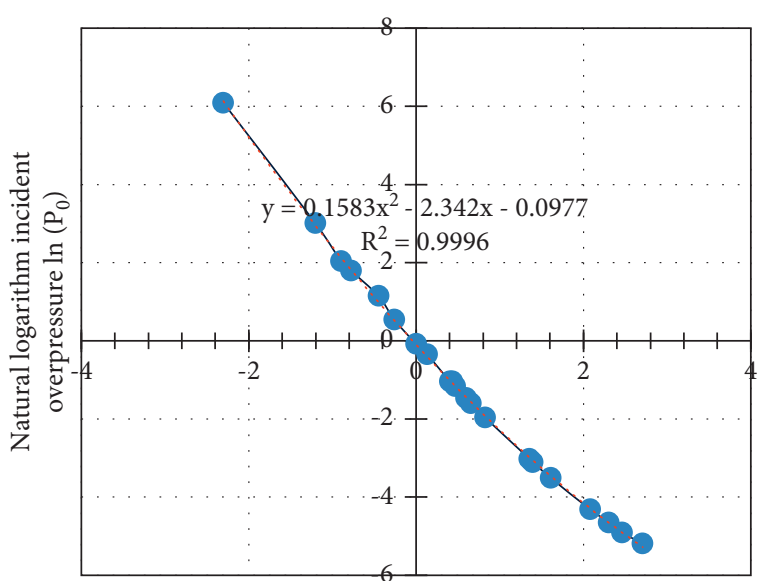

Natural logarithm scale distance $\ln Z$

(a)

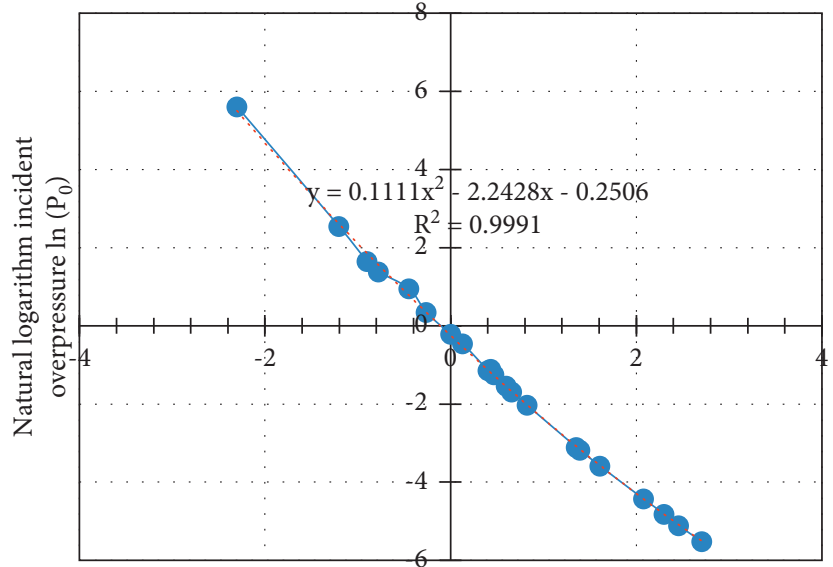

Natural logarithm scale distance lnZ lower limit

(b)

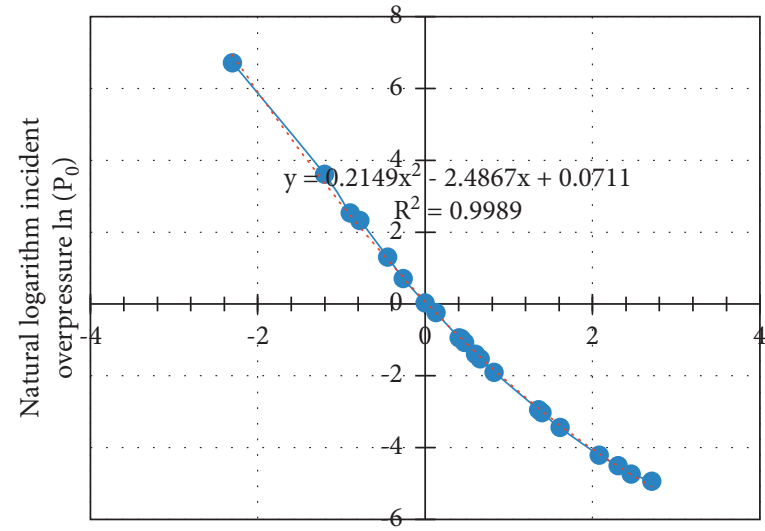

Natural logarithm scale distance $\ln Z$ upper limit

(c)

FIGURE 11: Fitting curve of incident overpressure, 95\% confidence interval with scaled distance. (a) Fitting curve of incident overpressure. (b) Lower limit of incident overpressure fitting curve. (c) Upper limit of incident overpressure fitting curve.

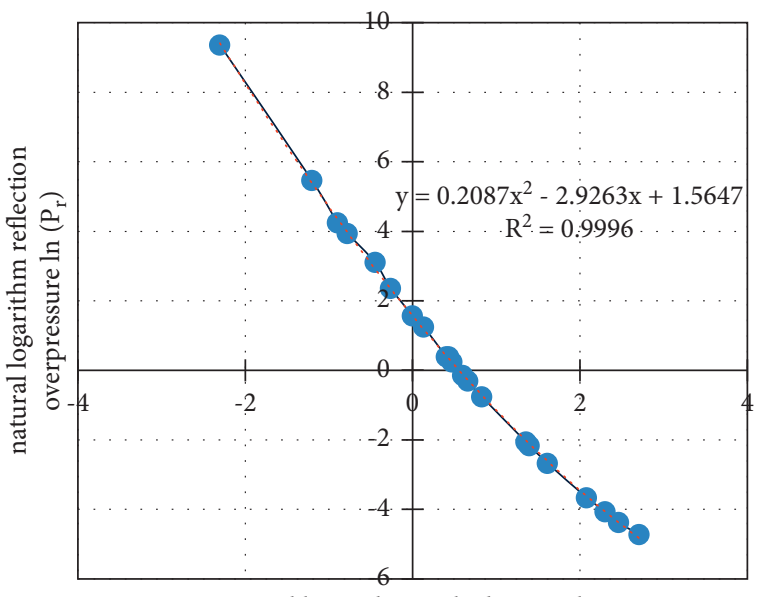

Natural logarithm scale distance $\ln Z$

(a)

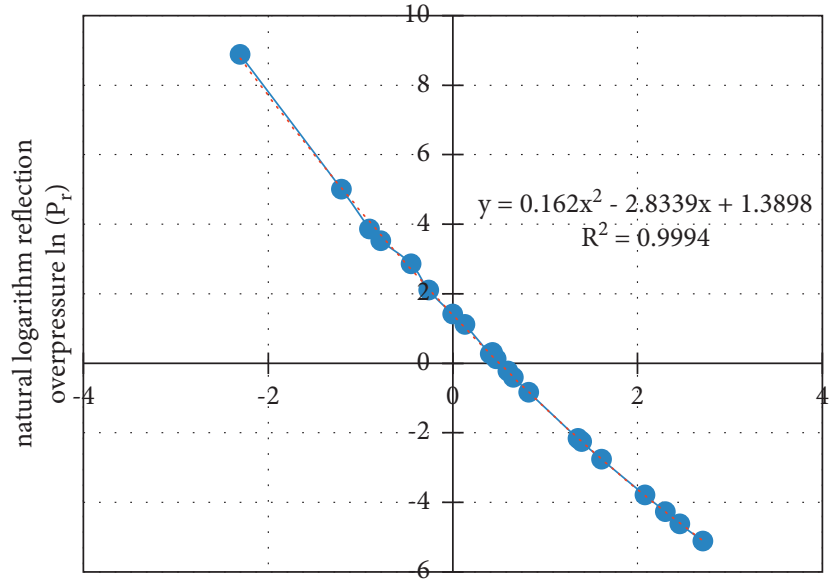

Natural logarithm scale distance $\operatorname{lnZ}$ lower limit

(b)

Figure 12: Continued. 


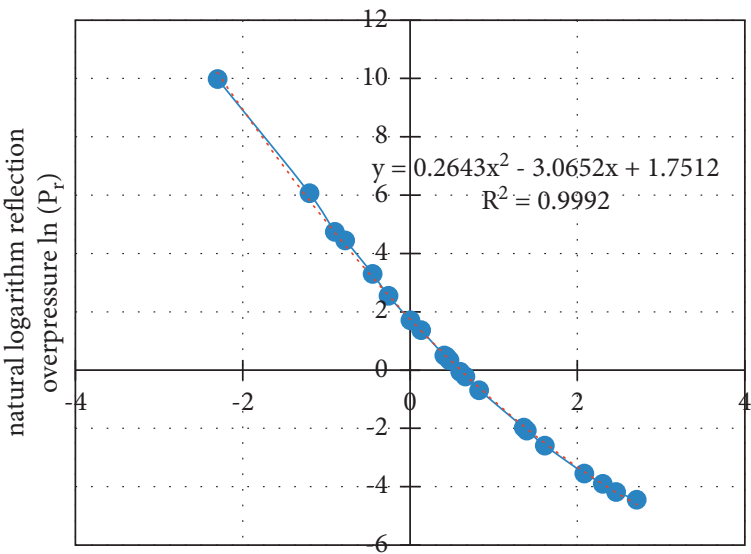

Natural logarithm scale distance $\operatorname{lnZ}$ upper limit

(c)

FIGURE 12: Fitting curve of reflection overpressure, $95 \%$ confidence interval with scaled distance. (a) Fitting curve of reflection overpressure. (b) Lower limit of reflection overpressure fitting curve. (c) Upper limit of reflection overpressure fitting curve.

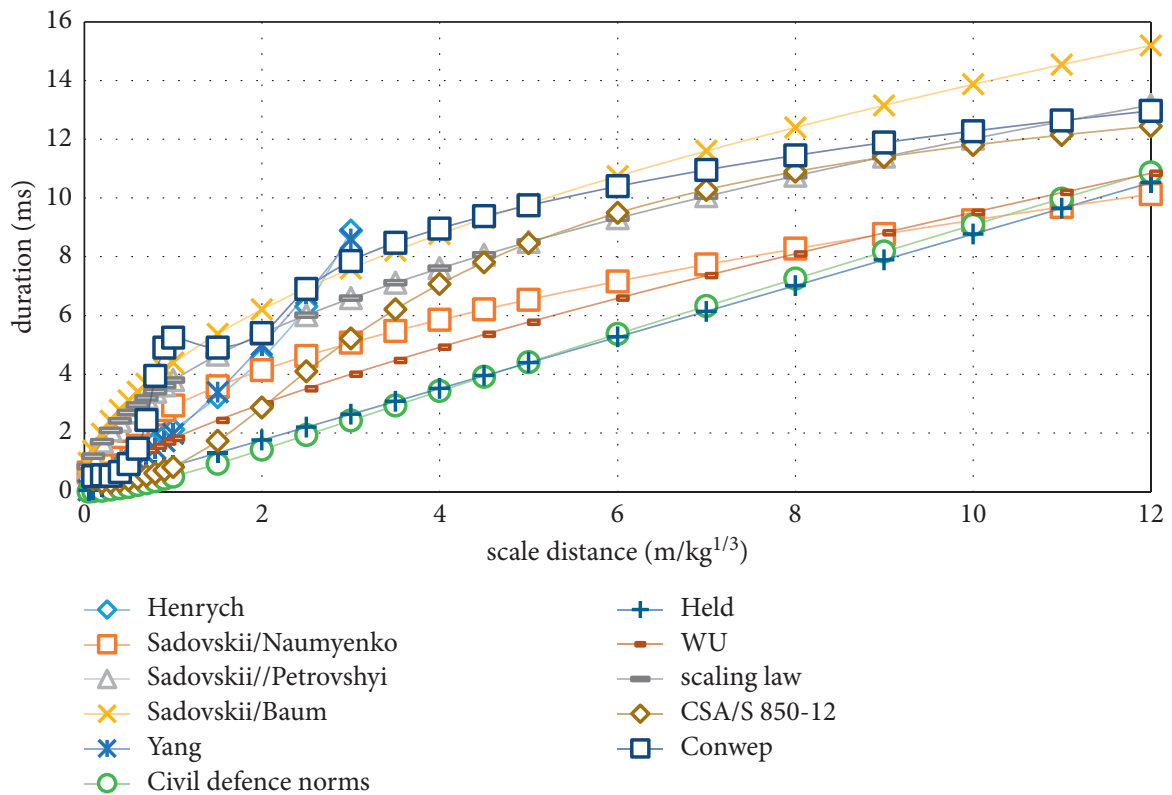

(a)

FIgURE 13: Continued. 


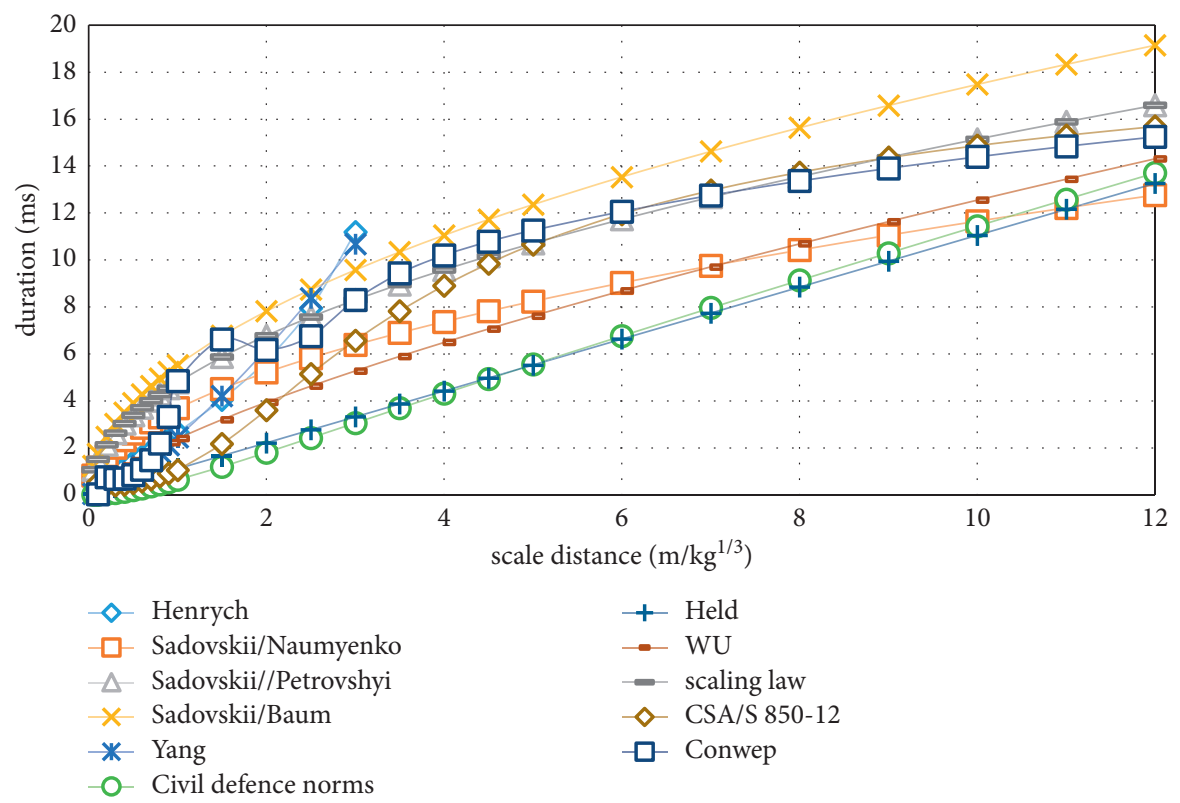

(b)

Figure 13: Relationship between duration and scaled distance under different explosive equivalents. (a) Explosive equivalent $25 \mathrm{~kg}$. (b) Explosive equivalent $50 \mathrm{~kg}$.

In the equation, the unit of $t$ is ms, the unit of $w$ is $\mathrm{kg}$, the unit of $P_{\text {so }}$ is $\mathrm{MPa}$, and the unit of $i_{\text {so }}$ is $\mathrm{Pa}$-s.

$\mathrm{Wu}$ and Hao [23] suggested using Henrych's research results and giving the formula for calculating the overpressure duration of air explosions as follows:

$$
\left.t=1.9 Z^{1.3} \text { (ascent) }+0.5 Z^{0.72} W^{0.4} \text { (downcomer }\right)(\mathrm{ms}) .
$$

Sui [51] obtained the calculation formula of duration according to explosion similarity law as follows:

$$
\frac{t}{\sqrt[3]{W}}=1.35 \sqrt{Z}, \quad R>12 R_{0}
$$

Canadian specification CSA/S 850-12 [4] gives the calculation formula of reflection overpressure and reflection impulse when the ground explosion occurs. Thus, the duration of overpressure can be inversely calculated. Among them, the calculation formula of reflection impulse is as follows:

$$
\begin{aligned}
\ln \frac{i_{r}}{\sqrt[3]{W}}= & 6.7853-1.3466 \ln Z+0.1010 \ln ^{2} Z \\
& -0.0112 \ln ^{3} Z, \quad 0.06<Z<39.67
\end{aligned}
$$

The unit of $i_{r}$ is KPa-ms.

4.2. Experimental Duration Data. Similar to the experimental overpressure data, 125 datasets were collected. The experimental data related to the blast loading duration are shown in Table 4 . Only 87 datasets were useable. In the experiments, the measured load duration is the total duration of exponentially declining overpressure. To facilitate statistical comparisons, all durations were converted into triangular durations form. The conversion principle was that the positive impulse and overpressure peak value of the exponential blast loading and triangular blast loading were consistent. It can be seen from Table 4 that, under the same conditions, the duration of blast loading has high discreteness.

By analyzing the theoretical duration formulas (30)-(39), it was found that, unlike the formulas of overpressure, the ratio of duration to the cube root of charge mass (i.e., the proportional time) was only related to the single parameter of scaled distance. Therefore, the data from theoretical calculations and experimentally measured data were changed into the proportional time data, and the relationship between the proportional time and the scaled distance was studied to determine the probability distribution of duration.

4.3. Duration Probability Distribution and Formula Derivation. Using the explosion overpressure duration data, the histograms of the proportional time $(t / \sqrt[3]{W})$ for different scaled distances were drawn, as shown in Figure 14. Combined with the distribution characteristics of the duration histograms, the K-S and Lilliefors goodness-of-fit tests of proportional time probability distributions for different 


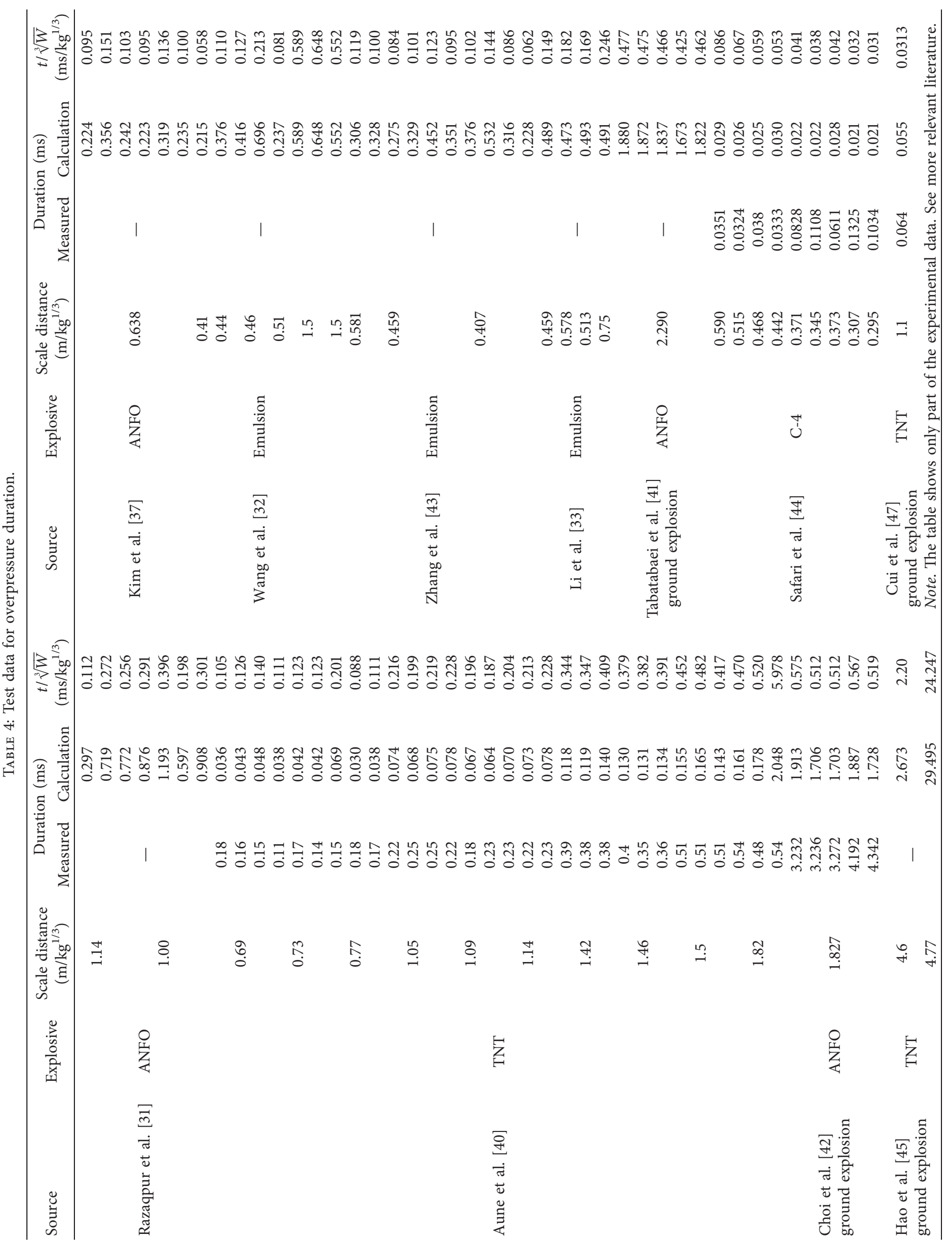




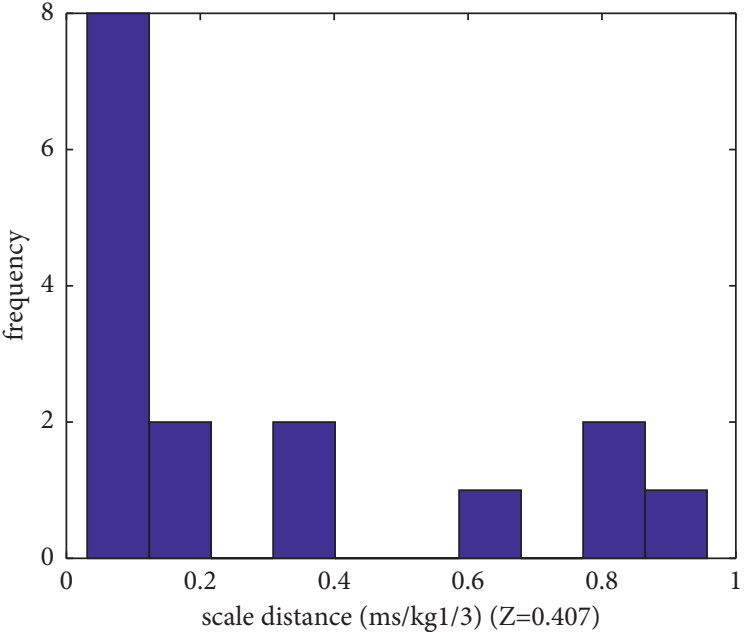

histogram

(a)

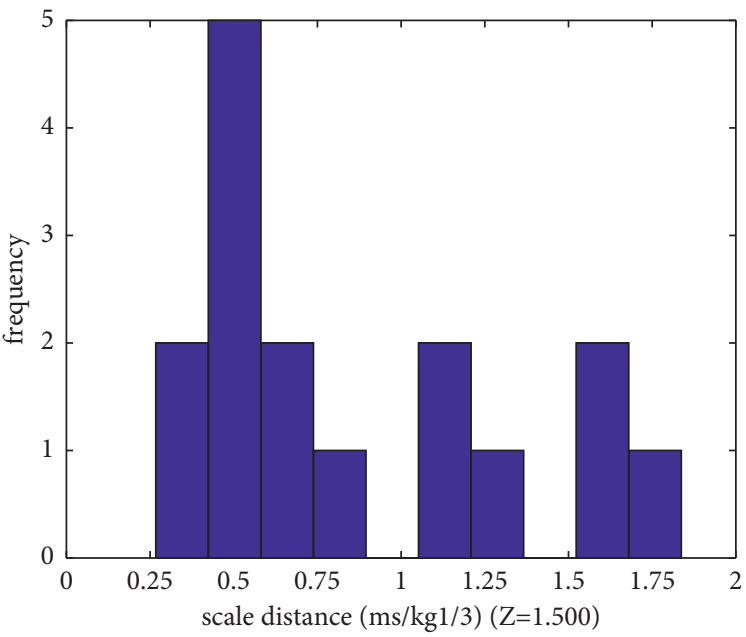

histogram

(c)

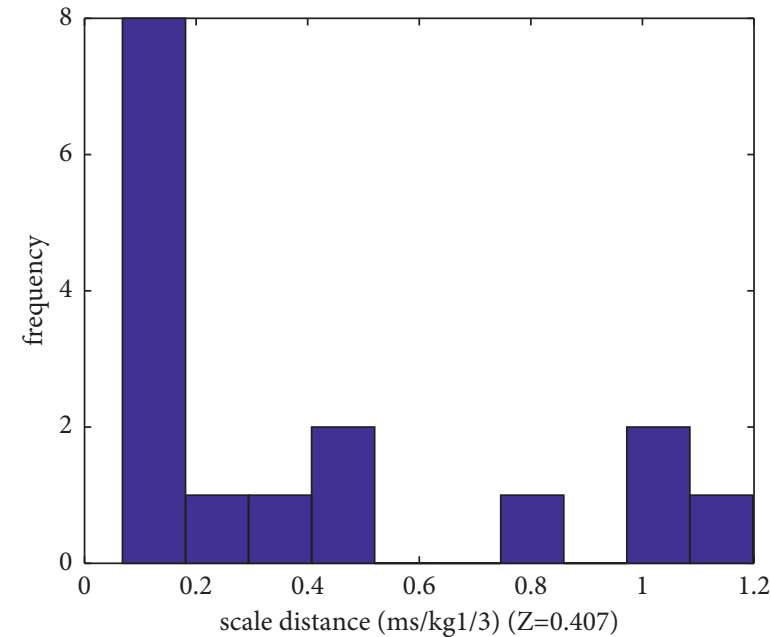

histogram

(b)

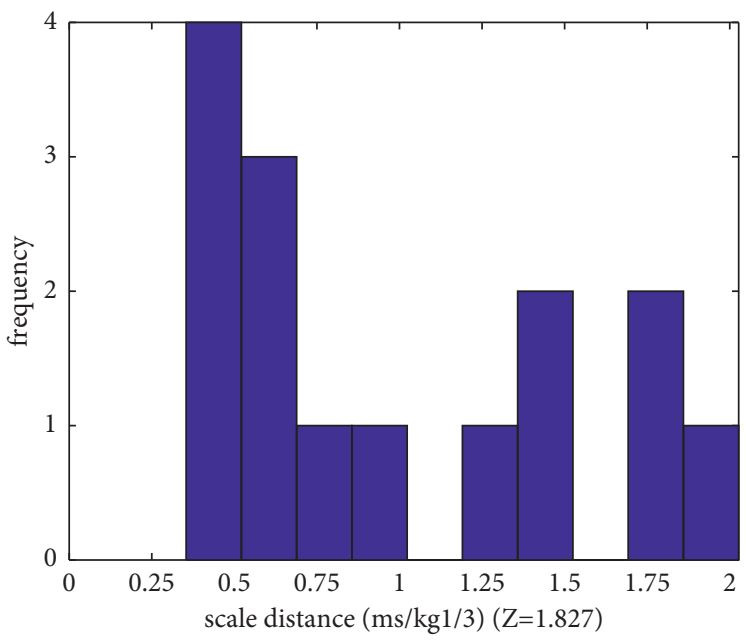

histogram

Figure 14: Duration histogram under different scaled distance. (a) Scale distance $(Z=0.407)$. (b) Scale distance $(Z=0.638)$. (c) Scale distance $(Z=1.500)$. (d) Scale distance $(Z=1.827)$.

scaled distances were carried out. The results showed that the proportional times for different scaled distances differed considerably and no specific probability distribution was acceptable. Therefore, the statistical data of proportional time for different scaled distances were used directly. The relationship between the proportional time and the scaled distance can be obtained by the least square method, as shown in Figure 15.

The function formula of proportional time with scaled distance is as follows:

$$
\frac{t}{\sqrt[3]{W}}=0.12821 Z^{3}-0.49254 Z^{2}+1.0219 Z-0.01744
$$

The curve formulas corresponding to the upper and lower limits of $95 \%$ confidence interval are as follows:

$$
\begin{aligned}
\frac{t}{\sqrt[3]{W}=} & 0.09964 Z^{3}-0.39868 Z^{2}+0.9184 Z \\
& -0.09867 \text { (upper.limit) } \\
\frac{t}{\sqrt[3]{W}=} & 0.15755 Z^{3}-0.58869 Z^{2}+1.12826 Z \\
& +0.06295 \text { (lower.Limit) }
\end{aligned}
$$

To compare the dispersion degree of the proportional time for different scaled distances, the coefficient of variation of the proportional time was calculated, as shown in Figure 16. As can be seen from Figure 16, for different scaled distances, the coefficients of variation of the proportional time were overall small, between 0.408 and 1.017. The variability becomes smaller with the increase in scaled distance. At the same time, the formula for the proportional time as a function of the scaled distance was highly reliable. 


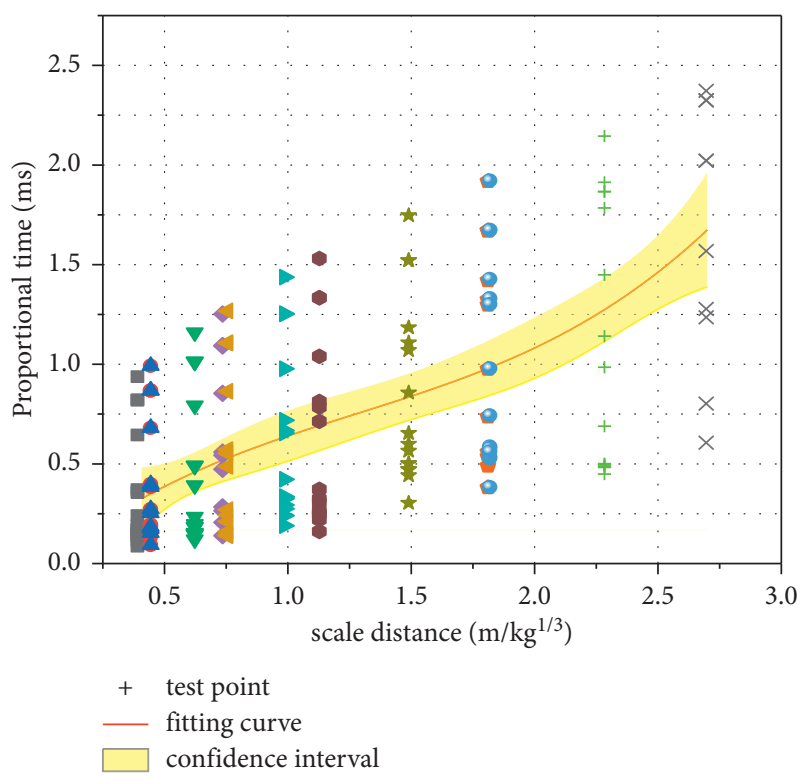

FIgURE 15: Relationship curve and confidence interval between proportional time and scaled distance.

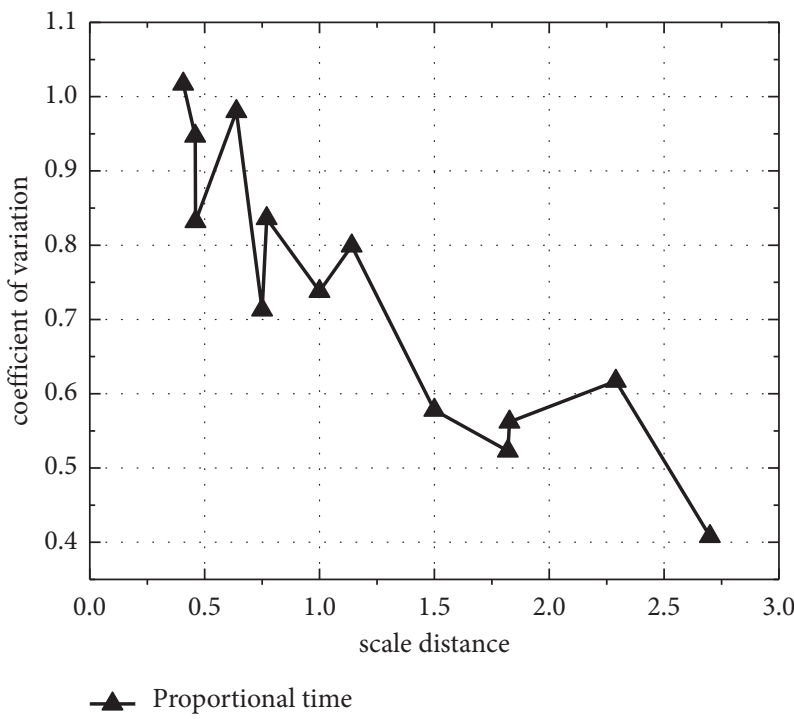

FiguRE 16: Variation coefficient of proportional time under different scaled distance.

\section{Conclusions}

By analyzing a large amount of blast loading experimental and theoretical data, the probability distribution of blast loading was studied. The main conclusions are as follows:

(1) Blast loading test data were affected by factors such as explosive type, equivalent mass and shape, and test environment. Both the overpressure and load duration varied. The experiments mostly used small equivalent explosives. The scaled distance was mostly concentrated in the range of $0.4-2.0 \mathrm{~m} / \mathrm{kg}^{1 / 3}$.

(2) A formula for the reflection coefficient was proposed by curve fitting to the vertical incidence data, and then a formula for the reflection overpressure using the incident overpressure was obtained.
(3) When the scaled distance was less than $0.5 \mathrm{~m} / \mathrm{kg}^{1 / 3}$, the probability density of explosion overpressure followed an exponential distribution, and the coefficient of variation of overpressure reached the maximum value of 1 . When the scaled distance was greater than $0.5 \mathrm{~m} / \mathrm{kg}^{1 / 3}$, the probability density of explosion overpressure followed a normal distribution. When the scaled distance was about $1.5-6 \mathrm{~m} / \mathrm{kg}^{1 / 3}$, the coefficient of variation was small, between 0.13 and 0.2 .

(4) For different scaled distances, no specific probability distribution function for the proportional duration could be selected, but the coefficient of variation of the proportional duration was relatively small, between 0.408 and 1.017 . 
(5) Using the data of explosion overpressure and proportional duration for different scaled distances, the formulas for the explosion overpressure and proportional duration and the $95 \%$ confidence upper and lower limit formulas were derived.

\section{Data Availability}

The data used to support the findings of this study are included within the article.

\section{Conflicts of Interest}

The authors declare that they have no conflicts of interest.

\section{Acknowledgments}

This work was supported by the National Natural Science Foundation of China (Grant no. 51608229). And the authors would like to express their gratitude to EditSprings (https:// www.editsprings.com/) for the expert linguistic services provided.

\section{References}

[1] TM5-855-1, Fundamentals of Protective Design for Conventional Weapons, US Department of the Army, Washington DC, USA, 1987.

[2] A. Castellano, J. Caltagirone, F. Sock, and N. Dobbs, TM-51300, "Design of Structures to Resist the Effects of Accidental Explosions, Technical Manual, US Department of the Army, Washington DC, USA, 1990.

[3] UFC 3-340-02, Structures to Resist the Effects of Accidental Explosions, Department of Defense Explosives Safety Board, New York, NY, USA, 2008.

[4] CSA/S 850-12, Design and Assessment of Buildings Subjects to Blast Loads, Canadian Standards Association, Toronto Canada, 2012.

[5] National Standard of the People's Republic of China, GB67222014, "Blasting Safety Regulations, China Standard Press, Beijing, China, 2014.

[6] National standards of the People's Republic of China, GB50038-2005, "Code for Design of Civil Air Defense Basements, China Plan Press, Beijing, China, 2005.

[7] H. Y. Low and H. Hao, "Reliability analysis of reinforced concrete slabs under explosive loading," Structural Safety, vol. 23, no. 2, pp. 157-178, 2001.

[8] D. Bogosian, J. Ferritto, and Y. Shi, "Measuring uncertainty and conservatism in simplified blast models," in Proceedings of the 30th Explosives Safety Seminar, Atlanta, Georgia, USA, August 2002.

[9] Z. X. Li, J. H. Lu, Y. C. Shi, and Y. Ding, "Reliability analysis of steel beams under uncertain blast loading," Engineering Mechanics, vol. 31, no. 4, pp. 112-118, 2014.

[10] J. H. Lu, Reliability Analysis of Steel Beams under Uncertain Explosion Loads, Tianjin University, Tianjin, China, 2012.

[11] Z. X. Li, Q. W. Ren, Y. C. Shi, and Y. Ding, "Research on blast load value in design of important building structures against terrorist explosions," Journal of Building Structures, vol. 37, no. 3, pp. 51-58, 2016.

[12] C. A. Mills, "The design of concrete structure to resist explosions and weapon effects," in Proceedings of the 1st
International Conference on Concrete for Hazard Protections, Edinburgh, UK, September 1987.

[13] R. E. Crawford, C. J. Higgins, and E. H. Bultmann, "The air force manual for design and analysis of hardened structures," USA Handbook for Design and Analysis of Protective Structures, Report AFWL-TR-74-102, Civil Nuclear System Corporation, New Mexico, 1980.

[14] G. H. Li, Anti - Explosion Dynamics of Engineering Structures, Shanghai Science and Technology Press, Shanghai, China, 1989.

[15] H. L. Brode, "Blast wave from a spherical charge," Physics of Fluids, vol. 2, no. 2, p. 217, 1959.

[16] H. L. Brode, "Numerical solutions of spherical blast waves," Journal of Applied Physics, vol. 26, no. 6, pp. 766-775, 1955.

[17] H. L. Brode, A Calculation of the Blast Wave from a Spherical Charge of TNT, University of Texas at Austin, Austin, TX, USA, 1961.

[18] J. Henrych and G. R. Abrahamson, The Dynamics of Explosion and its Use, Elsevier Scientific Pub. Co., Amsterdam NY, USA, 1979.

[19] J. Henrych and G. R. Abrahamson, The Dynamics of Explosion and its Use, Elsevier Scientific Pub. Co., Amsterdam NY, USA, 1979.

[20] G. F. Kinney and K. J. Graham, Explosive Shocks in Air, Springer-Verlag, Berlin, Germany, 1985.

[21] N. M. Newmark and R. J. Hansen, Design of blast resistant structures, New York: Shock and Vibration Hand book, Harris and Crede, McGraw-Hill, New York, NY, USA, 1961.

[22] W. E. Baker, P. Cox, P. Westine, and J. K. R. Strehlow, Explosion Hazards and Evaluation, Elsevier Scientific Pub. Co., " Amsterdam, The Netherlands, 1983.

[23] C. Wu and H. Hao, "Modeling of simultaneous ground shock and airblast pressure on nearby structures from surface explosions," International Journal of Impact Engineering, vol. 31, no. 6, pp. 699-717, 2005.

[24] I. A. Naumyenko and I. G. Petrovsky, The Shock Wave of a Nuclear Explosion, воен. издат. мии. сборокы CССР, Moscow, 1956.

[25] M. A. Sadovskii, Mechanical effects of air shock waves from explosions according to experiments, Nauka Press, Moscow, Explosion physics edition, 1952.

[26] X. H. Ye, Military Explosive Engineering, PLA Press, Beijing, China, 1999.

[27] J. I. Siddiqui and S. Ahmad, "Impulsive loading on a concrete structure," Proceedings of the Institution of Civil EngineersStructures and Buildings, vol. 160, no. 4, pp. 231-241, 2007.

[28] S. Ahmad, A. Elahi, J. Iqbal, M. A. Keyani, and A. G. A. Rahman, "Impulsive loading on reinforced concrete wall," Proceedings of the Institution of Civil Engineers Structures and Buildings, vol. 166, no. 3, pp. 153-162, 2013.

[29] J. Iqbal and S. Ahmad, "Improving safety provisions of structural design of containment against external explosion," in Proceedings of the International conference on opportunities and challenges for water cooled reactors in the 21st century, Internaltional Atomic Energy Agency (IAEA), Vienna, Austria, October 2011.

[30] M. Held, "Blast waves in free air," Propellants, Explosives, Pyrotechnics, vol. 8, no. 1, pp. 1-7, 1983.

[31] A. G. Razaqpur, A. Tolba, and E. Contestabile, "Blast loading response of reinforced concrete panels reinforced with externally bonded GFRP laminates," Composites Part B: Engineering, vol. 38, no. 5-6, pp. 535-546, 2007.

[32] H. Wang, C. Wu, F. Zhang et al., "Experimental study of largesized concrete filled steel tube columns under blast load," 
Construction and Building Materials, vol. 134, pp. 131-141, 2017.

[33] J. Li, C. Wu, H. Hao, and Z. Liu, "Post-blast capacity of ultrahigh performance concrete columns," Engineering Structures, vol. 134, pp. 289-302, 2017.

[34] H. W. Jin, Z. X. Liu, S. Y. Liu, and Y. Su, "Experimental study of ultra-high performance fiber reinforced concrete filled steel tube columns under blast loading," Building structure, vol. 46, no. 4, pp. 45-49, 2016.

[35] X. X. Liang, Z. Q. Wang, and R. N. Wang, "Deformation model and performance optimization research of composite blast resistant wall subjected to blast loading," Journal of Loss Prevention in the Process Industries, vol. 49, pp. 326-341, 2017.

[36] G. Q. Li, H. Y. Qu, T. C. Yang, Y. Lu, and S. W. Chen, "Experimental study on blast resistance of concrete filled steel tubular columns," Journal of Building Structures, vol. 34, no. 12, pp. 69-76, 2013.

[37] J. H. J. Kim and S. B. Kimand, J. K. Choi, Experiment study on blast loading response of frp-retrofitted rc slab structures," in Proceedings of the Asia-Pacific Conference on FRP in Structures, pp. 533-538, Brisbane, Australia, December 2019.

[38] S. Ahmad, A. Elahi, H. Pervaiz, A. G. A. Rahman, and S. Barbhuiya, "Experimental study of masonry wall exposed to blast loading," Materiales De Construccion, vol. 64, no. 313, p. e7, 2014.

[39] C. B. Ritchie, J. A. Packer, M. V. Seica, and X. L. Zhao, "Behavior of steel rectangular hollow sections subject to blast loading," Journal of Structural Engineering-asce, vol. 143, no. 12, Article ID 04017167, 2017.

[40] V. Aune, E. Fagerholt, K. O. Hauge, M. Langseth, and T. Børvik, "Experimental study on the response of thin aluminium and steel plates subjected to airblast loading," International Journal of Impact Engineering, vol. 90, pp. 106-121, 2016.

[41] Z. S. Tabatabaei, J. S. Volz, J. Baird, B. P. Gliha, and D. I. Keener, "Experimental and numerical analyses of long carbon fiber reinforced concrete panels exposed to blast loading," International Journal of Impact Engineering, vol. 57, pp. 70-80, 2013.

[42] J.-H. Choi, S.-J. Choi, J.-H. J. Kim, and K.-N. Hong, "Evaluation of blast resistance and failure behavior of prestressed concrete under blast loading," Construction and Building Materials, vol. 173, pp. 550-572, 2018.

[43] F. R. Zhang, C. Q. Wu, X. L. Zhao et al., "Experimental study of CFDST columns infilled with UHPC under close-range blast loading," International Journal of Impact Engineering, vol. 93, pp. 184-195, 2016.

[44] K. H. Safari, J. Zamani, S. M. R. Khalili, and S. Jalili, "Experimental, theoretical, and numerical studies on the response of square plates subjected to blast loading," The Journal of Strain Analysis for Engineering Design, vol. 46, no. 8, pp. 805-816, 2011.

[45] Y. F. Hao, H. Hao, Y. C. Shi, Z. Q. Wang, and R. q. Zong, "Field testing of fence type blast wall for blast load mitigation," International Journal of Structural Stability and Dynamics, vol. 17, no. 9, Article ID 1750099, 2017.

[46] A. C. Jacinto, R. D. Ambrosini, and R. F. Danesi, "Experimental and computational analysis of plates under air blast loading," International Journal of Impact Engineering, vol. 25, no. 10, pp. 927-947, 2001.

[47] Y. Cui, J. H. Zhao, C. G. Zhang, and S. S. Sun, "Research on pressure distribution of blast wave on the surface of CFST column based on explosion test and numerical simulation,"
Journal of Beijing University of Technology, vol. 40, no. 12, pp. 1828-1836, 2014.

[48] G. I. Pokrovskii and I. S. Fedorov, Effect of Shock and Explosion on Deformable media, Gos. Izd, 1957.

[49] F. A. Baum, K. P. Stanyukovich, and B. I. Shekhter, Physics of an Explosion, Army Engineer Research and Development Labs Fort Belvoir VA, Virginia, USA, 1959.

[50] Y. D. Yang, X. D. Li, and X. M. Wang, "Optimized fitting of characteristic parameters of explosion shock wave propagation in air," Explosive Materials, vol. 43, no. 1, pp. 13-18, 2014.

[51] S. Y. Sui, Terminal Effect, National Defense Industry Press, Beijing, China, 2000. 